\title{
Subacute ruminal acidosis phenotypes in periparturient dairy cows differ in ruminal and salivary bacteria and in the in vitro fermentative activity of their ruminal microbiota
}

\author{
H. Yang, ${ }^{1} \odot$ S. Heirbaut, ${ }^{1} \odot$ J. Jeyanathan, ${ }^{1} \odot$ X. P. Jing, ${ }^{1,2} \odot$ N. De Neve, ${ }^{1} \oplus$ L. Vandaele, ${ }^{3} \odot$ and V. Fievez ${ }^{1 *} \odot$ \\ ${ }^{1}$ Laboratory for Animal Nutrition and Animal Product Quality, Department of Animal Sciences and Aquatic Ecology, \\ Faculty of Bioscience Engineering, Ghent University, 9000 Ghent, Belgium \\ ${ }^{2}$ State Key Laboratory of Grassland and Agro-Ecosystems, International Centre for Tibetan Plateau Ecosystem Management, \\ School of Life Sciences, Lanzhou University, Lanzhou 730000, China \\ ${ }^{3}$ Animal Sciences Unit, Flanders Research Institute for Agriculture, Fisheries and Food, 9090 Melle, Belgium
}

\section{ABSTRACT}

Both ruminal microbial structure and functionality might play a role in inter-individual variation in susceptibility for subacute rumen acidosis (SARA) observed in dairy cows. The aims of this study were to determine whether differences between cows with distinct SARA susceptibility were reflected in distinct (1) ruminal microbial communities, (2) salivary bacterial communities, and (3) fermentative capacity of ruminal microbiota assessed in vitro. To test this hypothesis, rumen samples were collected via an esophageal tube on $21 \mathrm{~d}$ postpartum from 38 multiparous Holstein cows, which were classified into 4 groups differing in median and mean time of reticular $\mathrm{pH}$ below 6 as well as area under the curve of $\mathrm{pH}$ below 6.0. During the $21 \mathrm{~d}$ postpartum, all cows within a group fulfilled following criteria: susceptible ( $\mathrm{S}, \mathrm{n}=10$; mean or median $\geq 180 \mathrm{~min} / \mathrm{d}$ ), moderately susceptible (MS, $\mathrm{n}=7 ; 60 \mathrm{~min} / \mathrm{d}<$ mean time of $\mathrm{pH}$ below $6<180 \mathrm{~min} / \mathrm{d}$, and median time of $\mathrm{pH}$ below $6<180 \mathrm{~min} / \mathrm{d}$ ), moderately unsusceptible $(\mathrm{MU}, \mathrm{n}=11 ; 10 \mathrm{~min} / \mathrm{d}<$ mean $<60 \mathrm{~min} / \mathrm{d}$, and median time of $\mathrm{pH}$ below $6 \leq 30 \mathrm{~min} / \mathrm{d}$ ), or unsusceptible $(\mathrm{U}, \mathrm{n}=10 ;$ median $=0 \mathrm{~min} / \mathrm{d}$, and mean $<10 \mathrm{~min} / \mathrm{d})$. Groups did not differ in total daily dry matter intake nor in total, roughage, or concentrate intake during daily 6 -h time intervals. Rumen bacterial $\alpha$-diversity did not differ among groups, but $\beta$-diversity varied and bacterial 16S rRNA gene copy numbers were lower in $\mathrm{S}$ compared with U cows. The relative abundance of genera Streptococcus, Sharpea, Prevotellaceae_YAB2003, Succinivibrionaceae_UCG-001, Ruminococcus, and Ruminococcaceae_UCG-001 were higher in S compared with U cows. In contrast, Lachnospiraceae_ND3007 and Oscillospiraceae_V9D2013 were more abundant in U

\footnotetext{
Received August 4, 2021.

Accepted January 4, 2022.

*Corresponding author: Veerle.Fievez@UGent.be
}

cows. Although pH-associated, inter-animal differences were also observed in the salivary bacteria, common differences in ruminal and salivary bacterial genera were limited. The functionality of the rumen microbiota was evaluated in vitro through exposure of the microbial inoculum of $\mathrm{S}$ and $\mathrm{U}$ cows to an anaerobic buffer at $\mathrm{pH}$ 5.8 and 6.8 , in the presence of sterile supernatant of their own and of dry cows' rumen fluid $(2 \times 2$ design). Generally, the $\mathrm{S}$ inoculum produced more volatile fatty acids, except at low $\mathrm{pH}$ with dry cows' supernatant, where volatile fatty acid production was completely impaired and lactate accumulation was highest. Compared with the microbes of $\mathrm{U}$ cows, microbes of $\mathrm{S}$ cows showed less fermentative activity in situations with 2 stress factors (low $\mathrm{pH}$ and an unfamiliar environment, i.e., rumen fluid supernatant of dry cows).

Key words: subacute ruminal acidosis, periparturient period, inter-animal variation, bacterial community, in vitro fermentative activity

\section{INTRODUCTION}

The transition around parturition in dairy cows is characterized by a decrease in DMI, which is also manifested in a decreasing share of dietary roughage (Hayirli et al., 2003), as the greatly increased energy requirements of lactation demand more energy-dense diets with a greater proportion of concentrates (Grummer, 1995). Accordingly, the higher amounts of quickly fermentable carbohydrates in combination with lower proportions of physically effective fiber in such diets put cows at higher risk of SARA. Despite several measures and guidelines to prevent SARA, incidence rates of $23.3 \%$ were reported during the first week in lactation in a recent study with 249 dairy cows (VallejoTimarán et al., 2020). This could be related to interanimal variation in SARA susceptibility, resulting in part of the herd suffering from SARA when receiving the same diet and similar management (Plaizier et al., 
2008; Mohammed et al., 2012; Jing et al., 2018). Such inter-animal variation also may reduce the effectiveness within a dairy herd of herd-based dietary interventions to prevent and control SARA (Humer et al., 2018). Thus, the early prediction and understanding of SARA susceptibility in dairy cows is paramount to our continued ability to limit its prevalence and specifically target animals at risk. In this respect, earlier work by our group indicated that the first 3 wk after calving offers a window of opportunity to identify SARA susceptibility phenotypes in dairy cows, as inter-animal differences during this period seemed to largely persist over a long period (>1 yr; Jing et al., 2018). However, as SARA prevalence is roughly $20 \%$ (Plaizier et al., 2008), experiments under practical conditions during the transition period require a much larger number of animals than traditional SARA challenge experiments. Nevertheless, such experiments are highly relevant, as the effects of most experimentally induced SARA may be more severe than those of on-farm SARA (Khafipour et al., 2009b; Plaizier et al., 2018). Accordingly, it is questionable whether inter-animal variation observed under experimentally induced SARA challenges is representative of inter-animal differences encountered during the transition period under practical management conditions (i.e., gradual build-up of increased amounts of grains accompanied with low physically effective NDF feeding).

Variation in SARA susceptibility (either inter-animal variation or dietary SARA-induction) has been related to differences in the number of rumen prokaryotes and eukaryotes (e.g., Hook et al., 2011) as well as the composition of rumen bacterial communities (e.g., Mohammed et al., 2012), as assessed by quantitative PCR (qPCR) and 16S rRNA amplicon sequencing, respectively. Moreover, these differentiating rumen microbial communities also seem to respond differently to a grain-based SARA challenge (Khafipour et al., 2009a; Chen et al., 2012; McCann et al., 2016). Accordingly, in addition to the structure of the microbiome, its functionality to cope with different disturbances during transition might also differ among animals differing in SARA susceptibility. As well as dietary shifts, other abiotic factors in the ruminal environment could also create such disturbances (Fonty et al., 1993). Obviously, low rumen $\mathrm{pH}$ is the most known abiotic factor influencing microbial fermentation, particularly through inhibition of $\mathrm{pH}$-sensitive cellulolytic microorganisms (Chen et al., 2019). Nevertheless, other abiotic factors produced by ruminal microbiota, such as some essential growth factors (e.g., branched-chain volatile fatty acid, phenylpropanoic acid, and vitamins), can also facilitate growth and hence functionality of specific microbial communities (e.g., Fonty et al., 1993; Shaani et al., 2018), and antimicrobial compounds excreted by microbiota can actively interfere with other species' growth (e.g., Long and Azam, 2001). Accordingly, the microbial community and its functionality are adapted to the abiotic factors of their environment, and they may be disturbed by abiotic factors to which they are not adapted.

The current study included 38 dairy cows under practical management conditions during the transition period. We hypothesized that the inter-animal variation observed in SARA susceptibility during this period is reflected in abundance of prokaryotic and eukaryotic microbiota, rumen bacterial community composition, and resilience of the rumen microbiota to withstand abiotic disturbances. As oral samples can provide accurate information on the composition of animals' rumen microbiome (Kittelmann et al., 2015; Tapio et al., 2016), inter-animal variation in SARA is assumed to be reflected in the bacterial community recovered from oral samples. Furthermore, it was hypothesized that metataxonomic analysis of the ruminal and salivary bacteria allow inference of inter-animal differences in SARA susceptibility. Finally, resilience of rumen microbial functionality against abiotic disturbances was assessed in vitro through exposure to various $\mathrm{pH}$ conditions and microbial metabolites. An in vitro set-up was chosen to allow assessment of microbial functionality without interaction with the host. Distinct abiotic environments were created by varying $\mathrm{pH}$ and through addition of sterile supernatant either of the cow's own rumen fluid or of dry cows' rumen fluid. The latter was chosen because the diet of cows in the far-off dry period differs most from that of cows in early lactation. Therefore, the aims of this study were to determine whether differences between cows with distinct SARA susceptibility were reflected in (1) distinct ruminal microbial communities, both in terms of numbers and composition (bacteria only), (2) salivary bacterial community, and (3) fermentative capacity of the ruminal microbiota as assessed by in vitro exposure of the microbial inoculum from cows differing in SARA susceptibility to an anaerobic buffer at $\mathrm{pH} 5.8$ and 6.8 , in the presence of sterile supernatant of their own and of dry cows' rumen fluid.

\section{MATERIALS AND METHODS}

\section{Animals, Diets, and Group Assignment}

All animal experimental procedures were approved by the Ethics Committee of the Flanders Research Institute for Agriculture, Fisheries and Food, Melle, Belgium (EC 2018/329 and EC 2014/241). A total of 38 multiparous Holstein-Friesian dairy cows were included 
in the monitoring experiment, which took place at the research farm of the Institute for Agricultural, Fisheries and Food Research from 2 wk before the predicted calving date to 3 wk after calving in a period from March 2019 to October 2020.

From 3 wk before calving onward, cows received the same partial mixed ration as the lactating cows, supplemented with a dry cow mineral premix (Aveve) and on average $1 \mathrm{~kg}$ of balanced concentrate per cow per day. The partial mixed ration of the lactating cows was calculated to fulfill the needs of an average adult cow of $650 \mathrm{~kg}$, producing $26 \mathrm{~kg}$ of fat- and protein-corrected milk and was based on maize silage, prewilted grass silage, pressed beet pulp, soybean meal, and balanced compound feed (Table 1). The latter was linearly built up from d 3 to d 20 in lactation according to the scheme shown in Table 2. Cows were given the basal diet as 2 equal offerings at roughly 0730 and $1630 \mathrm{~h}$ ad libitum and had free access to water.

Reticular $\mathrm{pH}$ of all cows was monitored every 10 to 15 min using $\mathrm{pH}$ boluses (18 eBolus, eCow; 20 SmaXtec $\mathrm{GmbH}$ ). The 38 animals were divided into 4 groups based on $\mathrm{pH}$ criteria. For this, mean and median daily
$\mathrm{pH}$ values were assessed against a $\mathrm{pH}$ threshold. A $\mathrm{pH}$ threshold of 6.0 was chosen in the current study, as the reticular $\mathrm{pH}$ is generally 0.2 units higher than the rumen pH (Beauchemin et al., 2003; Neubauer et al., 2018). Further, the mean and median duration that $\mathrm{pH}$ dropped below 6 was calculated for each cow on a daily basis during the 3 -wk postpartum period. Then, the 38 cows were ranked from high to low based on mean and median of $\mathrm{pH}$ below 6 and divided into 4 approximately even-sized groups. As such, the 38 animals were classified based on the individual cow's mean or median (or both) time of $\mathrm{pH}$ below 6 , to roughly allocate between 20 and $30 \%$ of the cows to each group:

- Susceptible group (S; n = 10): mean or median time of $\mathrm{pH}$ below 6 at least $180 \mathrm{~min} / \mathrm{d}$;

- Moderately susceptible group (MS; $\mathrm{n}=7$ ): 60 $\mathrm{min} / \mathrm{d}<$ mean time of $\mathrm{pH}$ below $6<180 \mathrm{~min} / \mathrm{d}$, and median time of $\mathrm{pH}$ below $6<180 \mathrm{~min} / \mathrm{d}$;

- Moderately unsusceptible group (MU; n $=11$ ): $10 \mathrm{~min} / \mathrm{d}<$ mean time of $\mathrm{pH}$ below $6<60 \mathrm{~min} / \mathrm{d}$, and median time of $\mathrm{pH}$ below $6 \leq 30 \mathrm{~min} / \mathrm{d}$;

Table 1. Ingredients and chemical composition (\% of DM) of the diet offered from 3 wk before calving (Closeup) to the first $2 \mathrm{~d}$ of lactation as well as the diets offered on d 3 and d 20 in lactation (Lac3 and Lac20) ${ }^{1}$

\begin{tabular}{|c|c|c|c|}
\hline Item & Close-up & Lac3 & Lac20 \\
\hline Maize silage & 34.4 & 32.1 & 24.8 \\
\hline Grass silage & 34.4 & 32.1 & 24.8 \\
\hline Beet pulp & 8.42 & 7.84 & 6.07 \\
\hline Urea & 0.140 & 0.130 & 0.101 \\
\hline Straw & 0.957 & 0.892 & 0.690 \\
\hline Barley & 1.10 & 1.02 & 0.789 \\
\hline Maize & 4.16 & 3.88 & 3.00 \\
\hline Soybean meal & 7.98 & 11.1 & 7.37 \\
\hline Balanced compound feed $\mathrm{A}^{2}$ & - & 2.45 & 10.8 \\
\hline Covasoy $^{3}$ & - & 2.45 & 5.40 \\
\hline Balanced compound feed $\mathrm{B}^{2}$ & 6.72 & 6.12 & 16.2 \\
\hline Mineral premix $^{4}$ & 1.68 & - & - \\
\hline \multicolumn{4}{|l|}{$\begin{array}{l}\text { Chemical composition, \% of DM } \\
\text { (unless noted otherwise) }\end{array}$} \\
\hline DM (\% of fresh matter) & 39.2 & 44.0 & 54.3 \\
\hline $\mathrm{VEM}^{5}(\mathrm{VEM} / \mathrm{kg}$ of DM $)$ & 998 & 1,027 & 1,053 \\
\hline $\mathrm{CP}$ & 13.8 & 16.0 & 16.8 \\
\hline $\mathrm{FOM}^{6}$ & 59.2 & 59.1 & 58.7 \\
\hline Starch & 16.8 & 16.4 & 18.0 \\
\hline $\mathrm{NE}_{\mathrm{L}}^{7}(\mathrm{MJ} / \mathrm{kg}$ of $\mathrm{DM})$ & 6.89 & 7.09 & 7.27 \\
\hline
\end{tabular}

${ }^{1}$ Between d 3 and d 20, a linear shift from Lac3 to Lac20 took place through build-up of balanced compound feed A and B, Covasoy (FeedValid BV) and soybean meal; see Table 2 for details.

${ }^{2}$ Balanced compound feed A and B; see Table 2 for details.

${ }^{3}$ Covasoy $=$ formaldehyde-treated soybean meal to bypass rumen degradation.

${ }^{4}$ Contains $2.2 \mathrm{~g}$ of $\mathrm{Ca}, 39.5 \mathrm{~g}$ of $\mathrm{P}, 0 \mathrm{~g}$ of $\mathrm{K}, 81.6 \mathrm{~g}$ of $\mathrm{Mg}, 30.1 \mathrm{~g}$ of Na, 2,000 mg of choline chloride, $20 \mathrm{mg}$ of calcium iodate, $15 \mathrm{mg}$ of cobalt sulfate, $1,000 \mathrm{mg}$ of copper sulfate, 1,250 mg of manganese oxide, 2,500 $\mathrm{mg}$ of zinc sulfate, $40 \mathrm{mg}$ of sodium selenite, 1,000,000 IU of vitamin A, 200,000 IU of vitamin D3, 4,400 $\mathrm{mg}$ of vitamin E.

${ }^{5} \mathrm{VEM}=$ feed unit lactation (Van Es, 1975).

${ }^{6} \mathrm{FOM}=$ fermented OM (Tamminga et al., 1994).

${ }^{7}$ Calculated based on the Belgian-Dutch net energy evaluation system; that is, 1,000 VEM $=6.9 \mathrm{MJ}$ of $\mathrm{NE}_{\mathrm{L}}$ (Van Es, 1975). 
- Unsusceptible group $(\mathbf{U} ; \mathrm{n}=10)$ : median time of $\mathrm{pH}$ below $6=0 \mathrm{~min} / \mathrm{d}$, and mean time $\mathrm{pH}$ below $6<10 \mathrm{~min} / \mathrm{d}$.

Individual daily median and mean time of $\mathrm{pH}$ below 6 , as well as the number of days with more than $330 \mathrm{~min}$ with $\mathrm{pH}$ below 6 during the 3 -wk postpartum period, are given in Table 3. Moreover, these 4 groups of cows concomitantly differed from each other in daily median and mean time of $\mathrm{pH}$ below 6 and mean daily area under the curve of pH below $6.0(P<0.001$; Table 4). Within the first $3 \mathrm{wk}$ in lactation, the $\mathrm{U}$ and $\mathrm{MU}$ groups did not show any day where time of $\mathrm{pH}<6.0$ exceeded $330 \mathrm{~min} / \mathrm{d}$, whereas a significantly larger number of such days were observed in the MS and S groups (Table 4). Three cows (S5, severe hypocalcemia; $\mathrm{S} 7$, severe lameness; S8, hypocalcemia) in the S group and 2 cows (MU2 and MU6, displaced abomasum) in the MU group showed some signs of clinical disease on some days during the 21-d monitoring period.

\section{Feeding Behavior}

Individual feed intake was monitored throughout the trial using roughage intake control feeding bins (Insentec, Hokofarm Group), except during the period around calving. During lactation, concentrate intake was monitored at the automatic concentrate providers (Greenfeed, C-Lock Inc.; DeLaval) and in the herringbone milking parlor (DeLaval). The raw data of roughage intake were checked for overlapping visits of the same animal as well as for outliers of visiting time or feed intake, according to the approach described by Mensching et al. (2020).

Data of 4 daily time intervals of $6 \mathrm{~h}$ each were compared. The time intervals were chosen in accordance with the rumen sampling time (i.e., at 0900 h). Accordingly, the following time intervals were considered: 0300 to 0900,0900 to 1500,1500 to 2100 , and 2100 to $0300 \mathrm{~h}$. For each interval the mean dry matter intake (concentrates, roughage, and total DMI) was calculated during a $3-\mathrm{d}$ period, from $2 \mathrm{~d}$ before sampling to the day of sampling. The number of meals was calculated based on the intake pattern at the roughage intake control bins. Visits were split into meals using a threshold of 28.7 min between visits (De Mol et al., 2016).

\section{Collection of Rumen Samples and Saliva}

On $21 \mathrm{~d}( \pm 1 \mathrm{~d})$ postpartum, salivary samples were collected $2 \mathrm{~h}$ after the morning feeding using a sterile sponge (Koala Universal Sponge) according to the procedure described by Tapio et al. (2016) and immediately snap frozen in liquid nitrogen. Afterward, a stomach tube was inserted via the mouth and esophagus into the rumen, and unfractionated samples of rumen contents were collected and filtered through a sieve with a pore size of $1 \mathrm{~mm}$ (Geishauser et al., 2012). After homogenizing, a sterile falcon tube of $15 \mathrm{~mL}$ was completely filled with rumen fluid and immediately transferred to the laboratory (within $30 \mathrm{~min}$ ) in a thermos flask filled with water at a temperature of $39^{\circ} \mathrm{C}$ for the in vitro experiment. Additionally, subsamples of rumen fluid were collected in cryovials and snap frozen in liquid nitrogen for microbial analysis. Snap-frozen saliva and rumen fluid samples were stored at $-80^{\circ} \mathrm{C}$ until DNA extraction.

\section{Bacterial Community Analysis Based on 16S rRNA Sequencing}

DNA Extraction. A total of $1 \mathrm{~mL}$ of both rumen fluid and saliva samples were centrifuged at $4^{\circ} \mathrm{C}$ for 15 min at $16,000 \times g$ to collect the pellets before genomic DNA extraction using the repeated bead beating plus column purification method (Yu and Morrison, 2004). The concentration and quality of extracted DNA was checked in a NanoDrop spectrophotometer (VWR International BVBA).

Table 2. Linear build-up between d 3 and 20 in lactation of the supplemental part of the diet, individually supplied to the cows during milking and via the concentrate dispenser $(\mathrm{kg} / \mathrm{d})$

\begin{tabular}{lccc}
\hline Item & Amount at d 3 & Build-up duration (d) & Amount at d 20 \\
\hline Balanced compound feed A ${ }^{1}$ & 0.2 & 20 & 2 \\
Balanced compound feed B $^{2}$ & 1.5 & 10 & 4 \\
Covasoy $^{3}$ & 0.2 & 7 & 1 \\
Soybean meal $^{2}$ & 0.3 & 20 & 0.3 \\
\hline
\end{tabular}

${ }^{1}$ Contains (g/kg of product): dry beet pulp (100), soybean meal (270), wheat (85), maize (430), molasses (70), salt (6), feed phosphate (10), micro minerals (10), lignin-sulfonate (10), chalk (4), magnesium oxide (5).

${ }^{2}$ Contains (g/kg of product): beet pulp (370), soybean meal (210), wheat (185), maize (120), molasses (50), salt (12), soy oil (10), feed phosphate (10), micro minerals (10), lignin-sulfonate (10), chalk (8), magnesium oxide (5).

${ }^{3}$ Covasoy $($ FeedValid BV $)=$ formaldehyde treated soybean meal to bypass rumen degradation. 


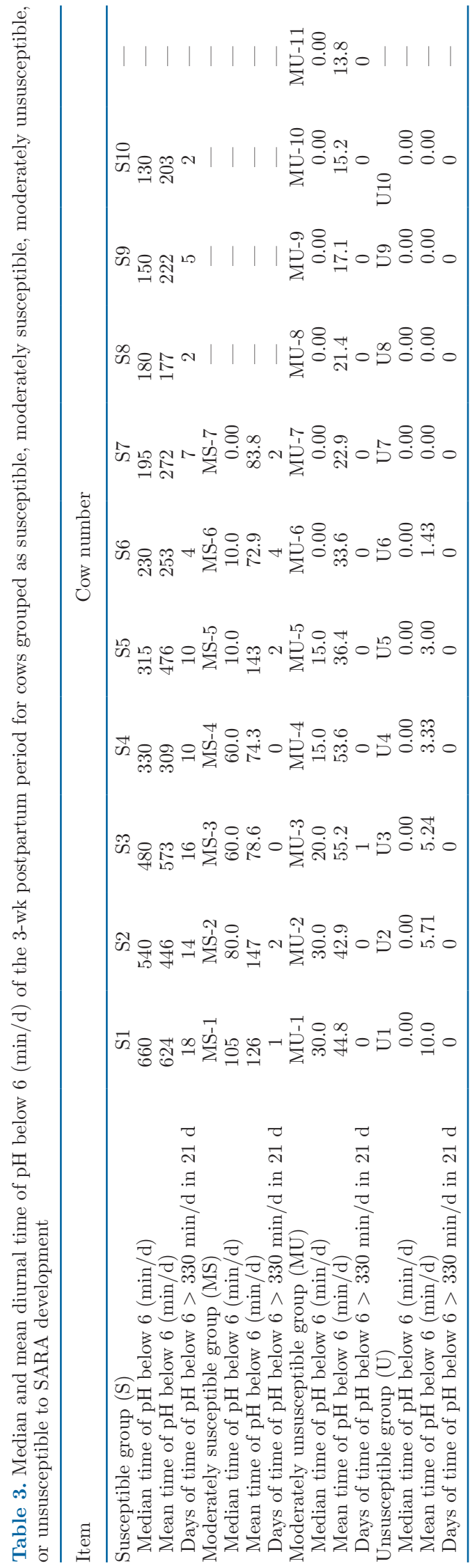

Bacterial 16S rRNA Gene Amplicon Sequencing and Data Mining. Extracted gDNA was submitted to Macrogen for library preparation and bacterial $16 \mathrm{~S}$ rRNA gene amplicon sequencing (V3-V4 region; primers: 344 forward and 806 reverse; Klindworth et al., 2013). Preparation of the amplicons barcoded library was based on the Illumina $16 \mathrm{~S}$ metagenomic sequencing library preparation protocol (https://support.illumina .com), and the sequencing was performed using Illumina MiSeq V3 technology $(2 \times 300 \mathrm{bp})$.

The amplicon sequencing data set was demultiplexed and barcodes were clipped off by the sequence provider. The amplicon sequencing data were analyzed using Quantitative Insights Into Microbial Ecology 2 (QIIME2, version 2020.08; Bolyen et al., 2019). The sequences were demultiplexed, barcodes were removed, and forward and reverse reads were imported into QIIME2. The DADA2 pipeline was used to detect and correct Illumina amplicon sequences, to remove primers and chimeric reads, and for the assembly into amplicon sequence variants (ASV; Callahan et al., 2016). A further filtering step was performed to remove lowabundance sequences with frequencies below $0.01 \%$ or present in less than 2 out of the 38 samples. Finally, to normalize the number of sequences per sample, a cutoff value $(30,114)$ was chosen based on $\alpha$-rarefaction curves for all samples. Taxonomy was assigned using a naïve Bayes classifier trained on the Silva database (Bokulich et al., 2018; SILVA Release 138, https://www .arb-silva.de/silva-license-information/) at 99\% similarity, followed by removal of the features of archaea and unassigned taxa. Sequence files associated with each sample have been submitted to the NCBI Sequence Read Archive (https://www.ncbi.nlm.nih.gov/sra; accession number PRJNA722858).

For saliva samples, a manual approach was applied to remove the potential oral ASV based on the description of Kittelmann et al. (2015) and published data from our group (Dewanckele et al., 2019). The removed as well as retained ASV were checked against literature to confirm that all the oral ASV were excluded, and possible ruminal ASV were retained. Two saliva samples were excluded from further analysis due to quality control failure. All potential rumen bacteria were retained. We came across many ASV of Streptococcus spp. Because Streptococcus spp. can be found in oral as well as in rumen samples, this species was initially not removed by the manual filtering approach. To determine whether the group of sequences assigned to Streptococcus with an unknown species affiliation could validly be eliminated from the data set, we created a phylogenetic tree of the genus Streptococcus, including the sequences obtained in this study and sequences downloaded from GenBank (https://www.ncbi.nlm.nih.gov/genbank/). Based on 
this phylogenetic tree, we removed the ASV clustered with known oral Streptococcus spp. After removal of the oral bacteria, the ASV table was normalized to 2,397 sequences per sample before further analysis in QIIME 2 (Dewanckele et al., 2019).

\section{Microbial Population Analysis by qPCR}

The abundance of $16 \mathrm{~S}$ rRNA genes of total bacteria, mcrA genes of methanogens, $18 \mathrm{~S}$ rRNA genes of protozoa, and $5.8 \mathrm{~S}$ rRNA of anaerobic fungi were quantified by $\mathrm{qPCR}$. The primers used for qPCR are presented in Supplemental Table S1 (https://doi.org/10.6084/m9 .figshare.19158098; Yang et al., 2022). Primer sets and qPCR conditions used were the same as reported for general bacteria (Denman and McSweeney, 2006), fungi (Edwards et al., 2008), protozoa (Carberry et al., 2012), and methanogens (Denman et al., 2007). The qPCR reactions were assayed in $12.5 \mu \mathrm{L}$ of reaction mixture containing $6.25 \mu \mathrm{L}$ of Maxima SYBR Green/ROX qPCR Master Mix $(2 \times)$ (ThermoFisher Scientific), 1 $\mu \mathrm{L}$ of primer mixture containing $0.5 \mu M$ concentrations of each primer, DNA (20 ng), and molecular water. Amplification of each target group was carried out in a 2-step cycling protocol (StepOne Real Time PCR System, Applied Biosystems) with the following program: initial denaturation at $95^{\circ} \mathrm{C}$ for $10 \mathrm{~min}, 35$ cycles at $95^{\circ} \mathrm{C}$ for $15 \mathrm{~s}$ (denaturation), $60^{\circ} \mathrm{C}$ for $1 \mathrm{~min}$ for annealing and extension. The melting curve was built by measuring fluorescence emissions with increased temperature from 60 to $95^{\circ} \mathrm{C}$ with ramps of $0.5^{\circ} \mathrm{C}$ every $15 \mathrm{~s}$. Duplicate qPCR quantification was performed on $20 \mathrm{ng}$ of extracted DNA. A plasmid containing a single copy of the targeted gene was used as qPCR standard. The copy numbers in the standards were calculated based on the DNA concentrations determined by the NanoDrop spectrophotometer (VWR International
BVBA). External standards were prepared and used in every qPCR run to enumerate the gene copies in the samples. The absolute quantity of each group of microorganisms was calculated using the respective standards and expressed as corresponding gene copies per milliliter of sample.

\section{In Vitro Experiment with Microbial Inoculum from $S$ and $U$ Cows}

In vitro simulations were performed using microbes collected from SARA-susceptible $(\mathrm{n}=10)$ and unsusceptible $(n=10)$ dairy cows to explore the fermentative capacity of these microbes when excluded from the interaction with their host. The microbes were exposed to 4 different conditions: low or normal pH (5.8 or 6.8, respectively) and sterile supernatant obtained from their own rumen fluid or rumen fluid collected from dry cows.

On the day of rumen fluid collection, an in vitro experiment was performed using inoculum collected from each cow separately. The inoculum collected from each cow was exposed to a buffer solution at $\mathrm{pH} 5.8$ or $\mathrm{pH}$ 6.8 and the supernatant derived from either the cow's own rumen fluid or from that of a dry cow (Figure 1). At the time of inoculum collection, cows' groupings were unknown, and, hence, incubations were carried out using inoculum of each of the 38 cows. However, further analysis was performed only on the 2 extreme groups $(\mathrm{S}, \mathrm{n}=10$; and $\mathrm{U}, \mathrm{n}=10)$.

Obtaining Sterile Supernatant from Rumen Fluid of Dry Cows. About $500 \mathrm{~mL}$ of rumen fluid was collected from 3 fistulated Holstein dry cows (6-7 yr old) housed in the same barn. These cows were fed 8 to $9 \mathrm{~kg}$ of maize silage (on DM basis) and $4.1 \mathrm{~kg}$ of chopped straw per day, supplemented with $1 \mathrm{~kg}$ of concentrate. The method to collect sterile supernatant

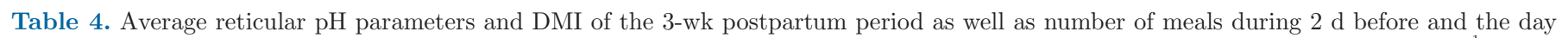
of sampling for cows grouped as susceptible, moderately susceptible, moderately unsusceptible, or unsusceptible to SARA development ${ }^{1}$

\begin{tabular}{|c|c|c|c|c|c|c|}
\hline Item & $\mathrm{S}$ & MS & MU & $\mathrm{U}$ & SEM & $P$-value \\
\hline \multicolumn{7}{|l|}{ Reticular pH } \\
\hline Median time of $\mathrm{pH}$ below $6(\mathrm{~min} / \mathrm{d})$ & $321^{\mathrm{a}}$ & $46.4^{\mathrm{b}}$ & $10.0^{\mathrm{c}}$ & $0.0^{\mathrm{d}}$ & 26.75 & $<0.001$ \\
\hline Mean time of $\mathrm{pH}$ below $6(\mathrm{~min} / \mathrm{d})$ & $356^{\mathrm{a}}$ & $104^{\mathrm{b}}$ & $32.5^{\mathrm{c}}$ & $2.78^{\mathrm{d}}$ & 26.963 & $<0.001$ \\
\hline Days with time of $\mathrm{pH}$ below $6>330 \mathrm{~min} / \mathrm{d}$ & $8.82^{\mathrm{a}}$ & $1.57^{\mathrm{b}}$ & $0.00^{\mathrm{c}}$ & $0.00^{\mathrm{c}}$ & 0.775 & $<0.001$ \\
\hline Mean daily area under curve $\mathrm{pH}$ below $6.0(\mathrm{pH} \times \min )$ & $882^{\mathrm{a}}$ & $293^{\mathrm{b}}$ & $50.1^{\mathrm{c}}$ & $3.85^{\mathrm{d}}$ & 77.548 & $<0.001$ \\
\hline $\mathrm{DMI}(\mathrm{kg} / \mathrm{d})$ & 19.6 & 20.0 & 19.8 & 21.9 & 0.43 & 0.164 \\
\hline \multicolumn{7}{|l|}{ Eating behavior $2 \mathrm{~d}$ before and day of sampling } \\
\hline Number of meals (times/d) & 7.07 & 8.43 & 7.33 & 7.60 & 0.221 & 0.277 \\
\hline
\end{tabular}

${ }^{\mathrm{a}-\mathrm{d}}$ Means within a row with different superscripts differ $(P \leq 0.05)$.

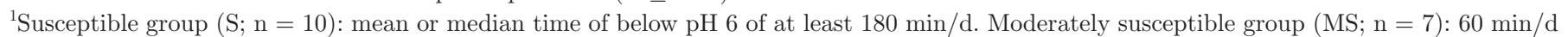

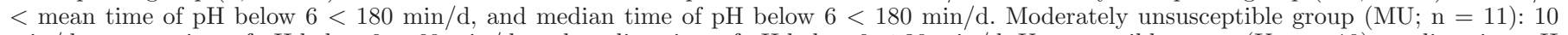

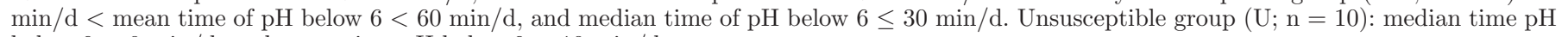
below $6=0 \mathrm{~min} / \mathrm{d}$, and mean time $\mathrm{pH}$ below $6<10 \mathrm{~min} / \mathrm{d}$. 
was based on Shaani et al. (2018). Accordingly, the collected rumen fluid was filtered through a kitchen sieve, mixed, and centrifuged at $25^{\circ} \mathrm{C}$ and $14,000 \times g$ for 15 min (Figure 1). The supernatant was then sterilized by filtering through a series of sterile vacuum filters (0.8-, $0.45-$, and 0.2- $\mu \mathrm{m}$ filters, Sigma-Aldrich). The filtered supernatant was divided into 50 aliquots $(15 \mathrm{~mL})$ and stored at $-20^{\circ} \mathrm{C}$ until use in the in vitro experiment, of which 38 aliquots were used in this study. On the incubation day, the number of aliquots required to perform the experiment were thawed and kept at $39^{\circ} \mathrm{C}$ under $\mathrm{CO}_{2}$ flushing.

Obtaining Sterile Supernatant and Microbes from Rumen Fluid of Cows Sampled on 21 Days Postpartum. Rumen fluid samples collected from cows on $21 \mathrm{~d}$ postpartum were centrifuged at $25^{\circ} \mathrm{C}, 14,000 \times$ $g$ for 15 min for the collection of sterile supernatant and was subjected to the same filtering process as described in the previous paragraph for dry cows. The sterile supernatant was kept in a $39^{\circ} \mathrm{C}$ warm water bath under continuous flushing with $\mathrm{CO}_{2}$ until the start of the in vitro experiment.
Cleaning Microbial Pellet and Mixing with Sterile Supernatant. The pellets, containing the rumen microbes, were recovered after centrifugation (collected from $15 \mathrm{~mL}$ of rumen fluid) and were washed with $15 \mathrm{~mL}$ of autoclaved buffer, through brief vortexing and mixing the pellets with buffer through pipette trituration. Afterward, this mixture was centrifuged at $25^{\circ} \mathrm{C}, 14,000 \times g$ for $15 \mathrm{~min}$, and the supernatant was removed. Oxygen exposure was minimized during all the previously mentioned steps by continuous flushing of $\mathrm{CO}_{2}$.

In Vitro Incubation of Mixed Microbes and Sterile Supernatant. The microbes collected from the periparturient cows were incubated with their own sterile supernatant as well as with the sterile supernatant obtained from the dry cows. Mixing the microbes with the sterile supernatant was performed under $\mathrm{CO}_{2}$ flushing. After mixing, each of the 2 mixtures $(15 \mathrm{~mL}$ of each microbial pellet and respective sterile supernatant) was equally divided into 2 anaerobic buffers at pH 6.8 and 5.8 [per liter: $51.59 \mathrm{~g}$ of 2-(N-morpholino) ethanesulfonic acid, $0.118 \mathrm{~g}$ of $\mathrm{MgCl}_{2} \cdot 6 \mathrm{H}_{2} \mathrm{O}, 8.30 \mathrm{~g}$ of

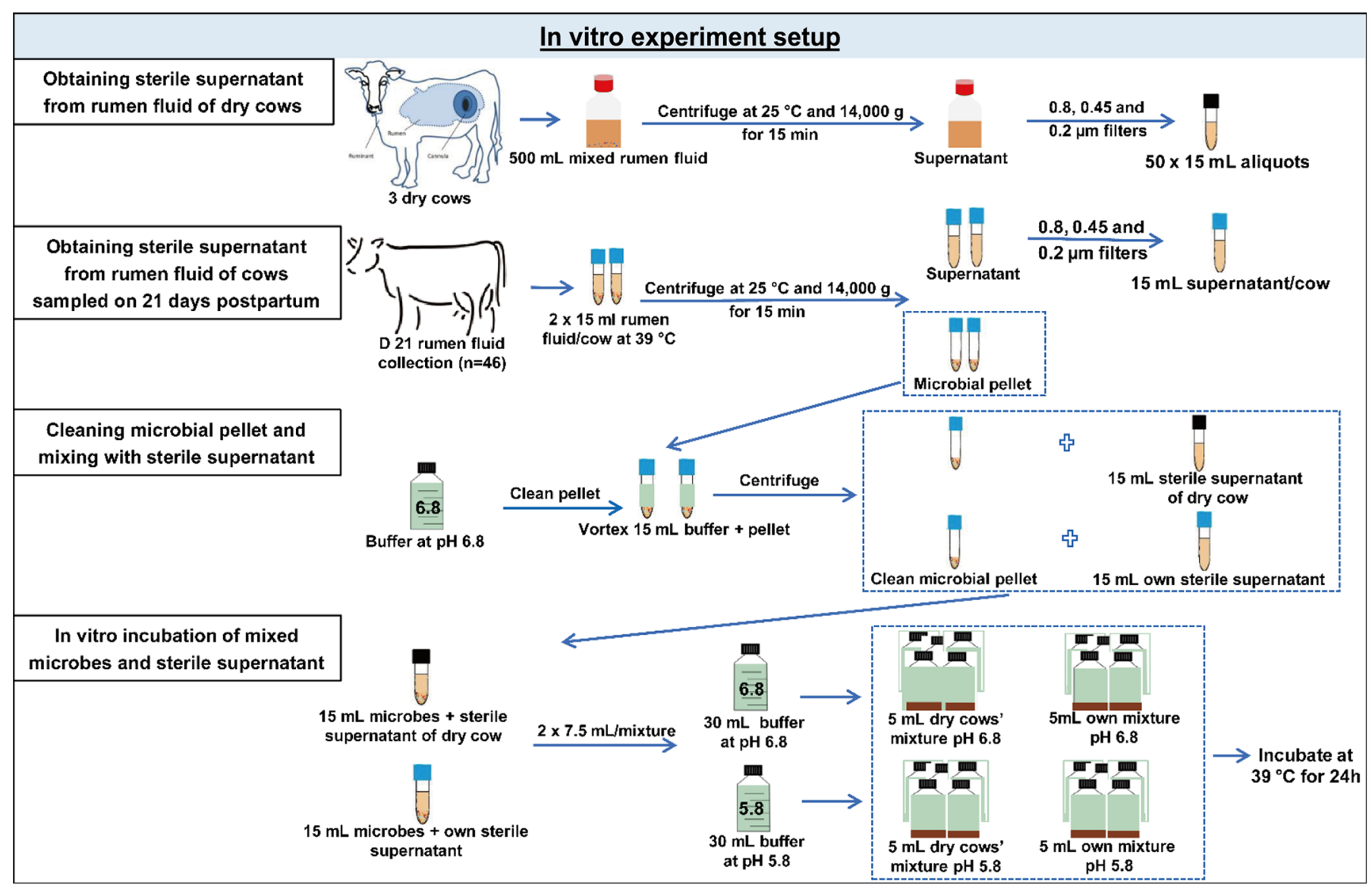

Figure 1. Scheme of the in vitro incubation set-up. 
$\mathrm{NaHCO}_{3}$, and $0.95 \mathrm{~g}$ of $\mathrm{NH}_{4} \mathrm{HCO}_{3}$ ] in a 1:4 ratio of rumen fluid to buffer. Buffer $\mathrm{pH}$ had been adjusted with 6 $M \mathrm{HCl}$ to 6.8 or 5.8 . The rumen fluid-buffer mixture (5 $\mathrm{mL}$ ) was transferred into an incubation flask under anaerobic conditions and incubated in triplicate for $24 \mathrm{~h}$ at $39^{\circ} \mathrm{C}$ in a shaking incubator (Edmund Bühler TH30; Edmund Bühler GmbH). Fifty milligrams of maize silage (proximate chemical composition, $\mathrm{g} / \mathrm{kg}$ of DM: CP, 67.3; crude fat, 35.5; NDF, 451; ADF, 218; ash, 56.0), lyophilized and stored at ambient temperature, was used as substrate for the incubation. After 24-h incubation, the flasks were taken out of the incubator and kept in an ice bath to stop microbial activity. Final pH (Hanna Instruments) was measured. One milliliter of the incubation fluid was collected for analysis of VFA and acidified with $100 \mu \mathrm{L}$ of formic acid, which contained the internal standard (10 mg of 2-ethyl butyric acid $/ \mathrm{mL}$ of formic acid). After 15-min centrifugation at $4^{\circ} \mathrm{C}$ and $22,000 \times g$, the supernatant was filtered and an aliquot transferred into a $1.5-\mathrm{mL}$ glass vial. Volatile fatty acids were analyzed through gas chromatography on an HP 7890A (Agilent Technologies) equipped with a Nukol column $(30 \mathrm{~m} \times 0.25 \mathrm{~mm} \times 0.25 \mu \mathrm{m}$, Supelco $)$ with a flame ionization detector (Dewanckele et al., 2020).

Lactate concentrations were determined according to Conway (1957). Net production of VFA and net accumulation of lactate were calculated by subtracting the amount in the incubation fluid before incubation from the amount after incubation.

\section{Data Analysis}

In Vitro Fermentation Data. Data were analyzed by $\mathrm{R}$ (R Core Team, 2020) using lme4 version 1.1.12 (Bates et al., 2015) according to the following model:

$$
\begin{aligned}
Y_{i j k l}=\mu+ & I_{j}+P_{k}+S U P_{l}+C_{i}\left(I_{j}\right)+\left(I_{j} \times P_{K}\right) \\
& +\left(I_{j} \times S U P_{l}\right)+\left(P_{K} \times S U P_{l}\right) \\
& +\left(I_{j} \times P_{K} \times S U P_{l}\right)+e_{i j k l},
\end{aligned}
$$

where $Y_{i j k l}=$ response variable (total VFA and lactate); $\mu=$ overall mean; $I_{j}=$ fixed effect of inoculum group (referring to the SARA susceptibility group of the inoculum donors; $j=\mathrm{S}$ or $\mathrm{U}) ; P_{k}=$ fixed effect of $\mathrm{pH}(k$ $=5.8$ or 6.8$) ; S U P_{l}=$ fixed effect of supernatant $(l=$ own or dry cow's supernatant); $C_{i}\left(I_{j}\right)=$ cow nested within inoculum group as random effect; $I_{j} \times P_{K}=$ interaction of inoculum group and $\mathrm{pH} ; I_{j} \times S U P_{l}=$ interaction of inoculum group and supernatant; $P_{K} \times$ $S U P_{l}=$ interaction between $\mathrm{pH}$ and supernatant; $I_{j} \times$ $P_{K} \times S U P_{l}=$ interaction of inoculum group, $\mathrm{pH}$, and supernatant; and $e_{i j k l}=$ residual error. The fixed effects $\left(I_{j}, P_{k}\right.$, and $\left.S U P_{l}\right)$ were forced into the model, and 2and 3 -way interactions were removed from the model if nonsignificant $(P>0.05$; also based on Akaike information criterion). Normality of residuals in the model was assessed via quantile-quantile plots and Shapiro-Wilk test, and homogeneity of variances was verified based on Levene test. Variables were log-transformed to meet normality assumptions if necessary. When the lme4 test indicated a significant 2- or 3-way interaction, $t$-tests were performed within $\mathrm{pH}$ conditions for comparison between supernatants (paired) and between inoculum groups (unpaired).

Reticular $p H$, DMI, Feeding Behavior, and $q P C R$. Data of feeding behavior during 4 time intervals were analyzed by 2-way repeated-measures ANOVA of the lme4 version 1.1.12 (Bates et al., 2015) package in $\mathrm{R}$ ( $\mathrm{R}$ Core Team, 2020) to examine the main effects of groups, time intervals, and their interactions, as well as random effects of cow. Data of reticular $\mathrm{pH}, \mathrm{DMI}$, and $\mathrm{qPCR}$ were analyzed in $\mathrm{R}$ (R Core Team, 2020) by one-way ANOVA of the car package (Fox and Weisberg, 2019) with groups as the main factor, after confirming normality of the data distribution assessed via quantile-quantile plots and Shapiro-Wilk test, and homogeneity of variances by the Levene test. Then, the differences between group means were assessed by Tukey's test for multiple comparisons. For data with non-normal distribution, a Kruskal-Wallis test followed by a pairwise Wilcoxon rank sum test was performed.

Bacterial Data. Bacterial sequencing profile were analyzed in QIIME2 (version 2020.08) and R (R Core Team, 2020). First, a nonparametric Kruskal-Wallis test was used to evaluate the differences of $\alpha$-diversity metrics across groups (QIIME2 software; version 2020.08). Additionally, distance-based (Bray-Curtis distances) PERMANOVA was carried out to check whether bacterial composition varies between groups in QIIME2 (Kunz et al., 2019). Analysis of composition of microbiomes (Mandal et al., 2015) tests were run in R (R Core Team, 2020) at phylum, family, and genus level to determine which bacterial groups were differentially abundant between different groups of cows. The differential taxa were computed controlling for false discoveries using Benjamini-Hochberg correction at $5 \%$ level of significance. Further, the taxa that differed significantly across groups detected by the analysis of composition of microbiomes test were subject to a Wilcoxon rank sum test to assess inter-group differences. Finally, a random forest algorithm was performed for in the randomForest (Liaw and Wiener, 2002) package in $\mathrm{R}$, with 10-fold cross-validation using the caret (Kuhn, 
Table 5. Gene copy numbers of rumen microbes analyzed by quantitative PCR in rumen fluid sampled on d 21 postpartum in relation to variation in SARA susceptibility over the first 3 wk postpartum ${ }^{1}$

\begin{tabular}{lcccccc}
\hline Item $\left(\log _{10} / \mathrm{mL}\right.$ rumen fluid $)$ & $\mathrm{S}$ & $\mathrm{MS}$ & $\mathrm{MU}$ & $\mathrm{U}$ & $\mathrm{SEM}$ & $P$-value \\
\hline Bacteria & $11.0^{\mathrm{b}}$ & $11.5^{\mathrm{ab}}$ & $11.2^{\mathrm{ab}}$ & $12.0^{\mathrm{a}}$ & 0.12 & 0.034 \\
Fungi & 7.48 & 7.31 & 7.33 & 7.47 & 0.102 & 0.917 \\
Methanogens & 10.9 & 10.1 & 10.1 & 10.7 & 0.21 & 0.453 \\
Protozoa & 11.6 & 12.7 & 11.2 & 11.0 & 0.30 & 0.319 \\
\hline
\end{tabular}

$\overline{\mathrm{a}, \mathrm{b}}$ Means within a row with different superscripts differ $(P \leq 0.05)$.

${ }^{1}$ Susceptible group $(\mathrm{S} ; \mathrm{n}=10)$ : mean or median time of below $\mathrm{pH} 6$ of at least $180 \mathrm{~min} / \mathrm{d}$. Moderately susceptible group (MS; $\mathrm{n}=7$ ): $60 \mathrm{~min} / \mathrm{d}<$ mean time of $\mathrm{pH}$ below $6<180 \mathrm{~min} / \mathrm{d}$, and median time of $\mathrm{pH}$ below $6<180 \mathrm{~min} / \mathrm{d}$. Moderately unsusceptible group (MU; $\mathrm{n}=11$ ): $10 \mathrm{~min} / \mathrm{d}<$ mean time of $\mathrm{pH}$ below $6<60$ $\min / \mathrm{d}$, and median time of $\mathrm{pH}$ below $6 \leq 30 \mathrm{~min} / \mathrm{d}$. Unsusceptible group $(\mathrm{U} ; \mathrm{n}=10)$ : median time $\mathrm{pH}$ below $6=0 \mathrm{~min} / \mathrm{d}$, and mean time $\mathrm{pH}$ below $6<10 \mathrm{~min} / \mathrm{d}$.

2008) package in $\mathrm{R}$. The number of trees in the forest was set to 500, the number of features available for splitting at each tree node (mtry) was tuned, and accuracy was used to select the optimal model using the largest value. Four saliva samples were excluded in the analysis due to the normalization of ASV table to 2,397 sequences per sample after removing potential oral bacteria, as mentioned for bacterial community analysis based on $16 \mathrm{~S}$ rRNA sequencing. Consequently, the 4 corresponding rumen samples were also removed. In total, 16 rumen and saliva samples from the 2 extreme SARA groups ( $\mathrm{S}, \mathrm{n}=7$; and $\mathrm{U}, \mathrm{n}=9$ cows) were used to classify the dairy cows' SARA susceptibility.

For all tests, a $P$-value of 0.05 was used to define significance, with trends declared at $0.05<P$-value $<$ 0.10 .

\section{RESULTS}

\section{Reticular-Ruminal pH Parameters, DMI, and Eating Behavior}

Grouping of the animals was based on the time below $\mathrm{pH} 6$ during the first $21 \mathrm{~d}$ postpartum, with groups concomitantly differing in daily median and mean time of $\mathrm{pH}$ below 6 , number of days with time of $\mathrm{pH}$ below 6 exceeding $330 \mathrm{~min} / \mathrm{d}$, and mean daily area under the curve of $\mathrm{pH}$ below 6.0. However, average daily DMI over this period did not differ. Additionally, DMI data of the days around sampling were assessed in some more depth: number of meals during the $2 \mathrm{~d}$ before sampling and the day of sampling did not differ between groups $(P>0.05)$, whereas total DMI tended to decrease in the $\mathrm{S}$ group during the time intervals of 0900 to 1500 h $(P=0.084$; Supplemental Table S2; https://doi.org/ 10.6084/m9.figshare.19158098; Yang et al., 2022) and 2100 to 0300 h $(P=0.051$; Supplemental Table S2). In contrast, no differences were found in roughage DMI and concentrate DMI throughout the day nor in total
DMI during the time blocks when the basal diet was distributed (i.e., 1500-2100 and 0300-0900 h).

\section{Rumen Bacteria, Fungi, Methanogens, and Protozoa Quantified by $q P C R$}

Gene copy numbers of rumen bacteria, fungi, methanogens, and protozoa assessed by qPCR are shown in Table 5. The $16 \mathrm{~S}$ rRNA gene copy numbers of bacteria were significantly greater in the $\mathrm{U}$ cows than in the $\mathrm{S}$ cows $(P=0.034)$, whereas the copy numbers of fungi, methanogens, and protozoa did not differ between groups $(P>0.05)$.

\section{Rumen Bacterial Community Composition}

$\alpha$-Diversity indices of rumen bacterial community (observed ASV, Faith_pd, evenness, and Shannon index) did not differ $(P>0.05)$ among groups (Supplemental Table S3; https://doi.org/10.6084/m9 .figshare.19158098; Yang et al., 2022). With regard to $\beta$-diversity compared by PERMANOVA, the BrayCurtis distances of the $\mathrm{U}$ cows differed from the $\mathrm{S}$ cows $(P=0.031$; Figure 2a and $2 \mathrm{c})$, whereas the $\mathrm{U}$ and $\mathrm{MU}$ cows tended to differ $(P=0.062$; Figure $2 \mathrm{c})$.

Relative abundances of bacterial families and genera, differing between cows varying in SARA susceptibility during the 3 -wk postpartum period, are shown in Table 6. Relative abundances of phyla to which these bacterial families or genera belong are also reported in Table 6. Overall, a total of 18 phyla were identified in 38 animals (Supplemental Table S4; https://doi .org/10.6084/m9.figshare.19158098; Yang et al., 2022); only 4 phyla exceeded a relative abundance of $1 \%$, with Firmicutes $(48.2 \pm 6.08 \%)$ and Bacteroidota (42.4 \pm $6.23 \%$; previously known as Bacteroidetes) representing the 2 dominant phyla. At genus level, Prevotella $(28.7$ \pm 0.66\%; Supplemental Figure S1a; https://doi.org/10 .6084/m9.figshare.19158098; Yang et al., 2022) is the 
dominant genus, followed by Succiniclasticum $(7.36 \pm$ 0.493\%; Supplemental Figure S1a). The relative abundances of the 2 predominant phyla and genera did not depend on the SARA grouping ( $P$-value adjusted for false discovery rate, $\left.\boldsymbol{P}_{\text {adj }}>0.05\right)$.

However, at the family and genus levels, 3 families and 8 genera differed between SARA groups (Table $6 ; P_{\text {adj }}$ $<0.05)$. Briefly, at family level, the relative abundances of Ruminococcaceae, Streptococcaceae, and vadinBE97 were higher in S and MS cows compared with MU and $\mathrm{U}$ cows $\left(P_{\mathrm{adj}}<0.05\right)$. At genus level, Ruminococcus, Sharpea, Coprococcus, Prevotellaceae_YAB2003, and Succinivibrionaceae_UCG-001 were more abundant in S cows and, in some cases in the MS cows, compared with $\mathrm{U}$ cows $\left(P_{\text {adj }}<0.05\right)$. Besides these differences, which were in accordance with the SARA classes, the genera Ruminococcaceae_UCG-001 and Streptococcus, within the phylum Firmicutes, were below the detection limit in the MS and MU cows, respectively, but the SARA extremes (S vs. U cows) did not differ. Additionally, differences in relative abundance of the Lachnospiraceae_ND3007 group and Oscillospiraceae_V9D2013 within the phylum Firmicutes did not follow the gradual SARA class differences.

Classification of SARA Susceptibility in Dairy Cows by Bacterial Community Using Random Forest Model. After manually removing potentially oral bacteria, a principal coordinate analysis was used to visualize the similarity of the saliva bacterial community and the rumen bacterial community (Figure 2). Despite the separation between the samples from saliva and rumen, some similarities were observed between the bacterial communities of these 2 sample types. Similar to the rumen bacterial community, Firmicutes $(37.9 \pm$ $5.41 \%)$ and Bacteroidota $(55.2 \pm 4.08 \%)$ represented the 2 dominant phyla in samples from saliva (Supplemental Table S5; https://doi.org/10.6084/m9.figshare .19158098; Yang et al., 2022). At genus level, 8 of the
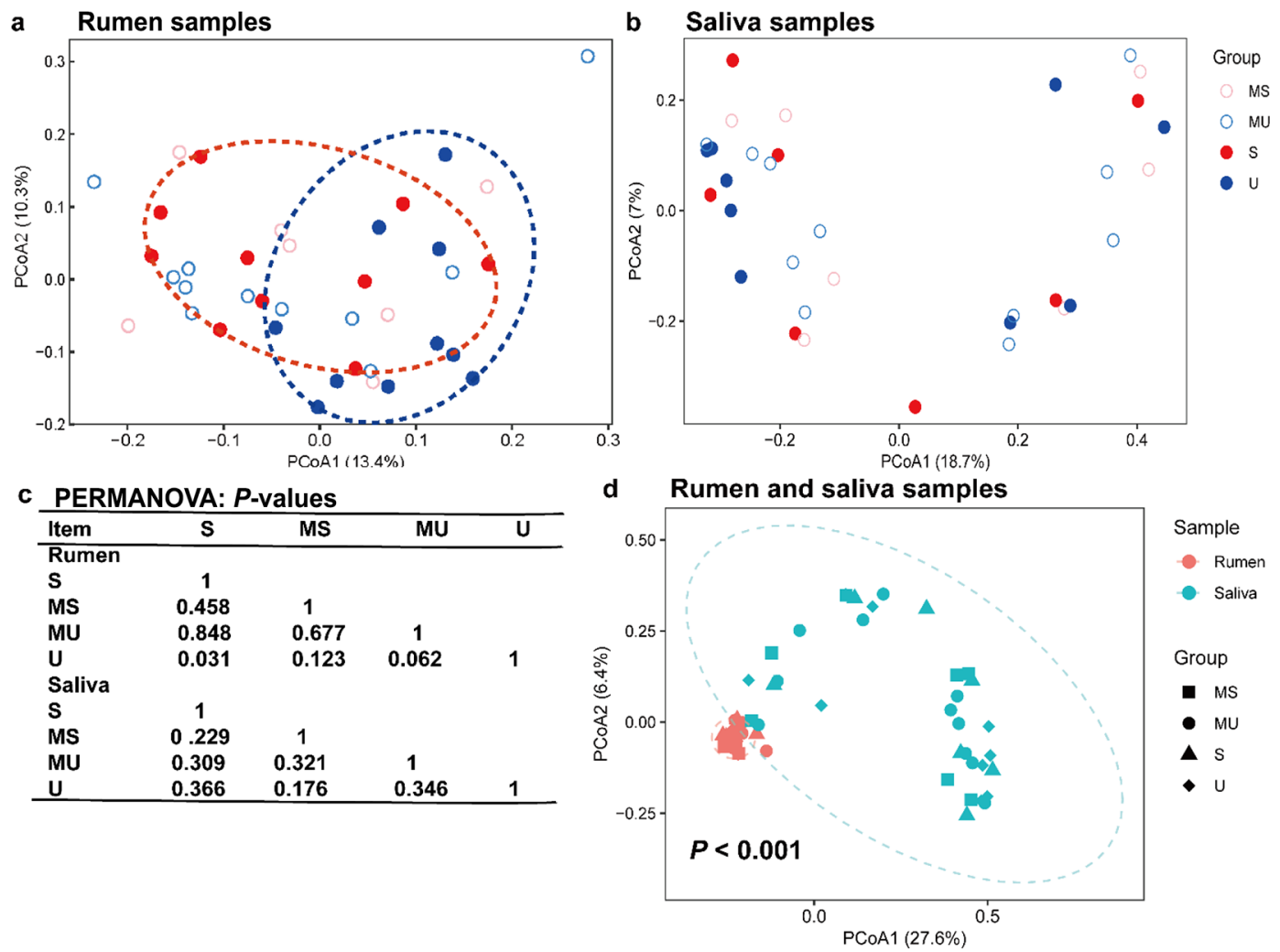

Figure 2. Principal coordinate analysis (PCoA) of the effect of sample type (a, rumen; b, saliva; d, rumen and saliva) on Bray-Curtis dissimilarities and $P$-values of the PERMANOVA model assessing differences in $\beta$-diversity (c) of the bacterial communities. Individual points in each plot represent the microbiome of an individual dairy cow; different colors represent samples from saliva or the rumen. Percentages shown along the axes represent the proportion of dissimilarities captured by $\mathrm{PCoA}$ in the 2-dimensional coordinate space. Susceptible group $(\mathrm{S} ; \mathrm{n}=$ 10): mean or median time of below $\mathrm{pH} 6$ of at least $180 \mathrm{~min} / \mathrm{d}$. Moderately susceptible group (MS; $\mathrm{n}=7$ ): $60 \mathrm{~min} / \mathrm{d}<\mathrm{mean}$ time of $\mathrm{pH}$ below $6<180 \mathrm{~min} / \mathrm{d}$, and median time of $\mathrm{pH}$ below $6<180 \mathrm{~min} / \mathrm{d}$. Moderately unsusceptible group $(\mathrm{MU} ; \mathrm{n}=11): 10 \mathrm{~min} / \mathrm{d}<\mathrm{mean}$ time of $\mathrm{pH}$ below $6<60 \mathrm{~min} / \mathrm{d}$, and median time of $\mathrm{pH}$ below $6 \leq 30 \mathrm{~min} / \mathrm{d}$. Unsusceptible group $(\mathrm{U} ; \mathrm{n}=10)$ : median time $\mathrm{pH}$ below $6=0 \mathrm{~min} / \mathrm{d}$, and mean time $\mathrm{pH}$ below $6<10 \mathrm{~min} / \mathrm{d}$. 


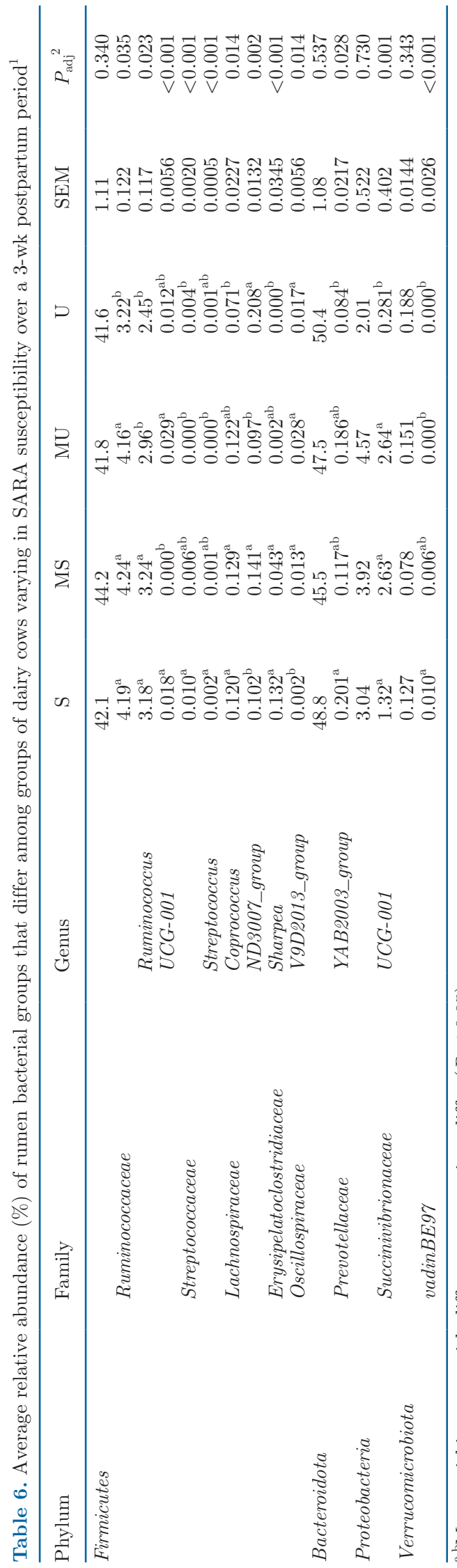

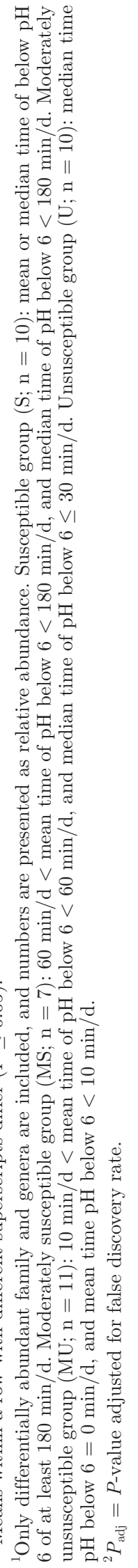

top 10 genera from saliva as also belonged to the top 10 genera in rumen samples (Supplemental Figure S1) with Prevotella $(28.7 \pm 6.33 \%$; Supplemental Figure S1b) being the dominant genus irrespective of SARA grouping, followed by Streptococcus (15.7 $\pm 3.59 \%$; Supplemental Figure S1b).

The possibility of correctly classifying cows into the $\mathrm{S}$ or $\mathrm{U}$ categories based on the bacterial community of saliva or rumen sampled 3-wk postpartum was tested through random forest classification (Figure 3 and 4). The 20 most predictive genera for classification of $\mathrm{S}$ versus $U$ cows, as assessed by the decrease in mean classification accuracy, showed some similarities between saliva and rumen samples (Figure 3). Among these 20 most predictive genera, saliva and rumen samples showed 3 common genera, such as uncultured Erysipelotrichaceae, Prevotella, and Anaerovibrio (Figure 3a and $3 \mathrm{c}$ ). These genera predominated in saliva and rumen samples of $\mathrm{S}$ cows (Figure 3b and 3d), although differences between $\mathrm{S}$ and $\mathrm{U}$ cows in Prevotella abundance of rumen samples were not clearly distinguished by the color code of the heatmap. The most predictive genus in rumen samples was Succinivibrionaceae_UCG001, whereas Bacteroides was the most predictive genus in saliva samples. The accuracy of the classification was $75 \%$ when relying on rumen bacterial genera (Figure $4 a)$ and $62.5 \%$ when relying on the bacterial genera of saliva samples (Figure 4b).

In Vitro Experiment with Microbial Inoculum from $S$ and $U$ Cows. Generally, microbes collected from SARA-susceptible cows produced more total VFA (TVFA) than microbes originating from SARAunsusceptible animals (Figure 5; $P_{\text {Group }}=0.049$ ). Also, TVFA was higher at $\mathrm{pH} 6.8$ than in incubations with a buffer solution at $\mathrm{pH} 5.8$ (Figure $5 ; P_{\mathrm{pH}}<0.001$ ). Exposure to dry cows' sterile supernatant rather than their own sterile supernatant reduced the fermentative capacity of the microbes, except when microbes from the $\mathrm{U}$ group were incubated at $\mathrm{pH} 5.8$, where a limited TVFA production was maintained, as observed in the $\mathrm{pH} 5.8$ incubations with cows' own sterile supernatant (Figure 5; $P_{\text {Supernatant } \times \text { Group } \times \mathrm{pH}}=0.054$ ). On the contrary, introduction of dry cows' sterile supernatant instead of cows' own in incubations at $\mathrm{pH} 5.8$ with microbes from the $\mathrm{S}$ group completely stopped TVFA production (Figure 5; $P_{\text {paired t-test }}<0.001 ; 29.9 \pm 9.58$ $\mu \mathrm{mol} /$ flask).

Hardly any net lactate accumulation was observed in incubations with microbes from unsusceptible cows incubated with their own supernatant at $\mathrm{pH} 6.8$ (Figure 6). Irrespective of the microbial origin ( $\mathrm{U}$ or $\mathrm{S}$ group), introduction of dry cows' sterile supernatant (Figure 6; $\left.P_{\text {Supernatant }}=0.028\right)$ as well as reduction of the buffer $\mathrm{pH}$ (Figure 6; $P_{\mathrm{pH}}=0.003$ ) enhanced net lactate accu- 
a
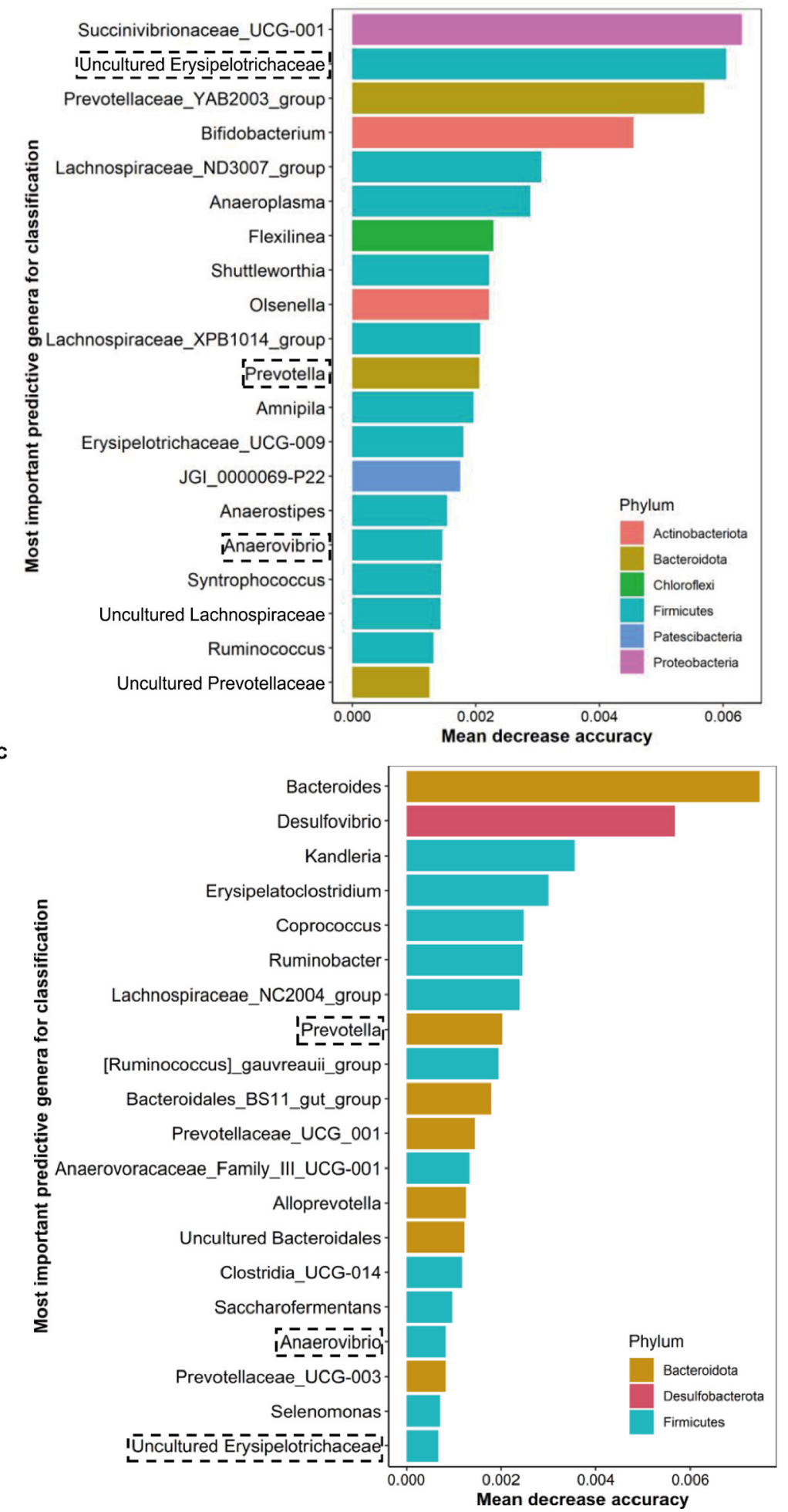

b

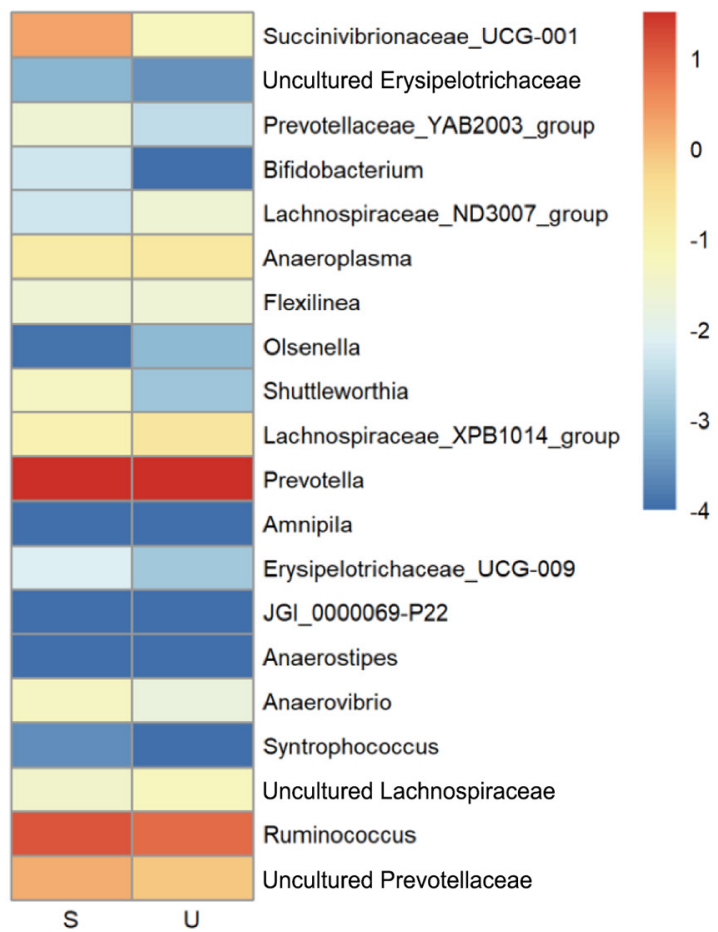

d

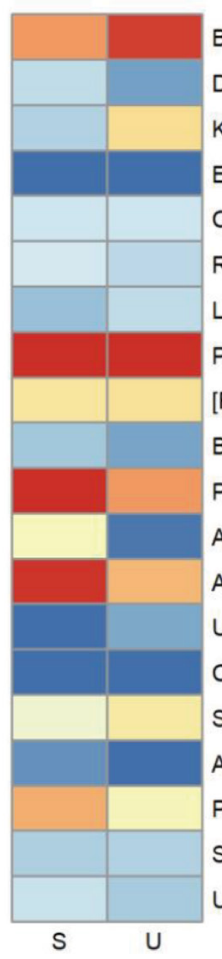

Bacteroides

Desulfovibrio

Kandleria

Erysipelatoclostridium

Coprococcus

Ruminobacter

Lachnospiraceae_NC2004_group

Prevotella

[Ruminococcus]_gauvreauii_group

Bacteroidales_BS11_gut_group

Prevotellaceae_UCG-001

Anaerovoracaceae_Family_III_UCG-001

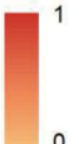

0

$-1$

$-2$

$-3$

Figure 3. The 20 most predictive genera to classify samples of SARA-susceptible (S) versus unsusceptible (U) cows based on bacterial analysis of rumen ( $\mathrm{a}$ and $\mathrm{b}$ ) and saliva samples (c and d). SARA susceptibility classification was based on time of $\mathrm{pH}$ below 6 during the first 3 wk postpartum (Table 3). Predictive importance of the bacterial genera was based on the mean decrease in accuracy of the random forest classification ( $(a$ and $c$ ) of cows that were susceptible $(S, n=7)$ or unsusceptible $(U, n=9)$ to SARA. Heat maps $(b$ and $d)$ indicate the log relative abundances of these bacterial genera. S cows: mean or median of time of $\mathrm{pH}$ below $6>180 \mathrm{~min} / \mathrm{d}$; U cows: median and mean of time of $\mathrm{pH}$ below 6 equals 0 and does not exceed $10 \mathrm{~min} / \mathrm{d}$, respectively. The common genera between rumen and saliva samples are indicated by dotted squares. 
mulation, with the highest accumulation in incubations where both were combined (Figure $6 ; P_{\text {Supernatant } \times \mathrm{pH}}=$ $0.045)$.

\section{DISCUSSION}

Inter-individual variation in SARA susceptibility has been shown among dairy cows (e.g., Mohammed et al., 2012; Khiaosa-ard et al., 2018). The origin of the inter-individual variation could be multifactorial, as previous studies have related inter-animal variation in SARA susceptibility to feeding behavior (Khiaosa-ard et al., 2018; Plaizier et al., 2018; Stauder et al., 2020), parity (Stauder et al., 2020; Khorrami et al., 2021), dietary factors (Khorrami et al., 2021), rumen microbial composition (Khafipour et al., 2009a; Chen et al., 2012; McCann et al., 2016), and genetics (Plaizier et al., 2018). Although variation in SARA susceptibility has been studied in relation to shifts in the rumen microbial community, these studies particularly followed a SARA induction protocol (e.g., Khafipour et al., 2009a; Chen et al., 2012; McCann et al., 2016). On the contrary, knowledge on inter-animal differences in the rumen microbial population under practical management conditions, during the SARA-risky transition period, is still lacking.

Inter-animal variation in reticular $\mathrm{pH}$ was observed among cows in the 3-wk postpartum period in the current study, which allowed us to classify cows into 4 groups based on reticular $\mathrm{pH}: \mathrm{S}, \mathrm{MS}, \mathrm{MU}$, and $\mathrm{U}$ cows
(Table 3). Nevertheless, it should be noted that not all cows classified in the susceptible group experienced SARA, according to the definition proposed by Zebeli et al. (2008) - that is, rumen $\mathrm{pH}$ below 5.8 (equivalent to reticular $\mathrm{pH}$ below 6.0) for more than $330 \mathrm{~min} / \mathrm{d}$. Over the entire 3 -wk postpartum period, only 4 out of the 10 susceptible cows showed a median or mean time of reticular $\mathrm{pH}$ below 6 (equivalent to rumen $\mathrm{pH}$ 5.8) exceeding $330 \mathrm{~min} / \mathrm{d}$, whereas all susceptible cows suffered from SARA (defined as reticular $\mathrm{pH}$ below 6.0 for more than $330 \mathrm{~min} / \mathrm{d}$ ) at least $2 \mathrm{~d}$ of the $21-\mathrm{d}$ measuring period.

Although only a limited number of animals met SARA conditions, sensu stricto, over the whole 3 -wk postpartum period, great inter-animal variation in reticular $\mathrm{pH}$ was observed, and the 4 groups differed in $\mathrm{pH}$ characteristics. Accordingly, we aimed to investigate the rumen bacterial composition in these 4 groups of cows. A higher bacterial copy number was observed in rumen fluid sampled $21 \mathrm{~d}$ postpartum from U cows. In contrast, none of the groups differed in $\alpha$-diversity indices, which was similar to the results found in cows differing in risk of SARA development undergoing a high-grain challenge (Mohammed et al., 2012; Wetzels et al., 2017; Dewanckele et al., 2019). However, $\beta$-diversity analysis revealed significant differences in the rumen bacterial community between $\mathrm{S}$ and $\mathrm{U}$ cows. Higher relative abundances of the genera Prevotellaceae_YAB2003, Ruminococcus, and Ruminococcaceae_UCG-001, Prevotella, and the family Ruminococ-
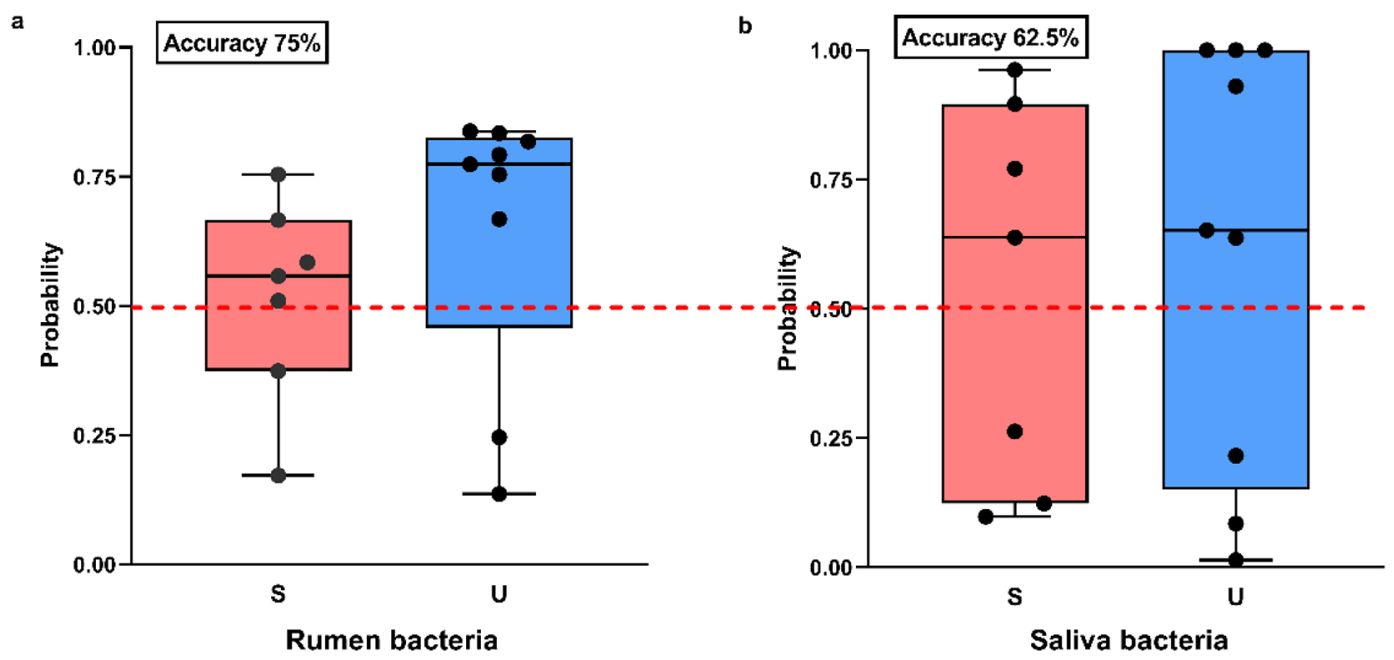

Figure 4. Predicted probability of the random forest model based on the bacterial community of ruminal fluid (a) and saliva (b) to discriminate cows that were susceptible $(\mathrm{S}, \mathrm{n}=7)$ or unsusceptible $(\mathrm{U}, \mathrm{n}=9)$ to SARA. Dots represent the probability of correct classification through the random forest model for each individual cow (10-fold cross-validation). SARA susceptibility classification was based on time of pH

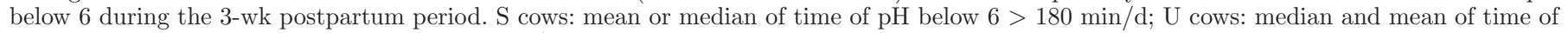
pH below 6 equals 0 and does not exceed $10 \mathrm{~min} / \mathrm{d}$, respectively. The upper and lower edges of boxes represent the upper and lower quartiles of

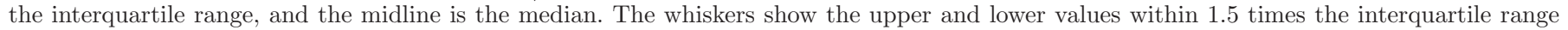
from the upper and lower quartiles. 


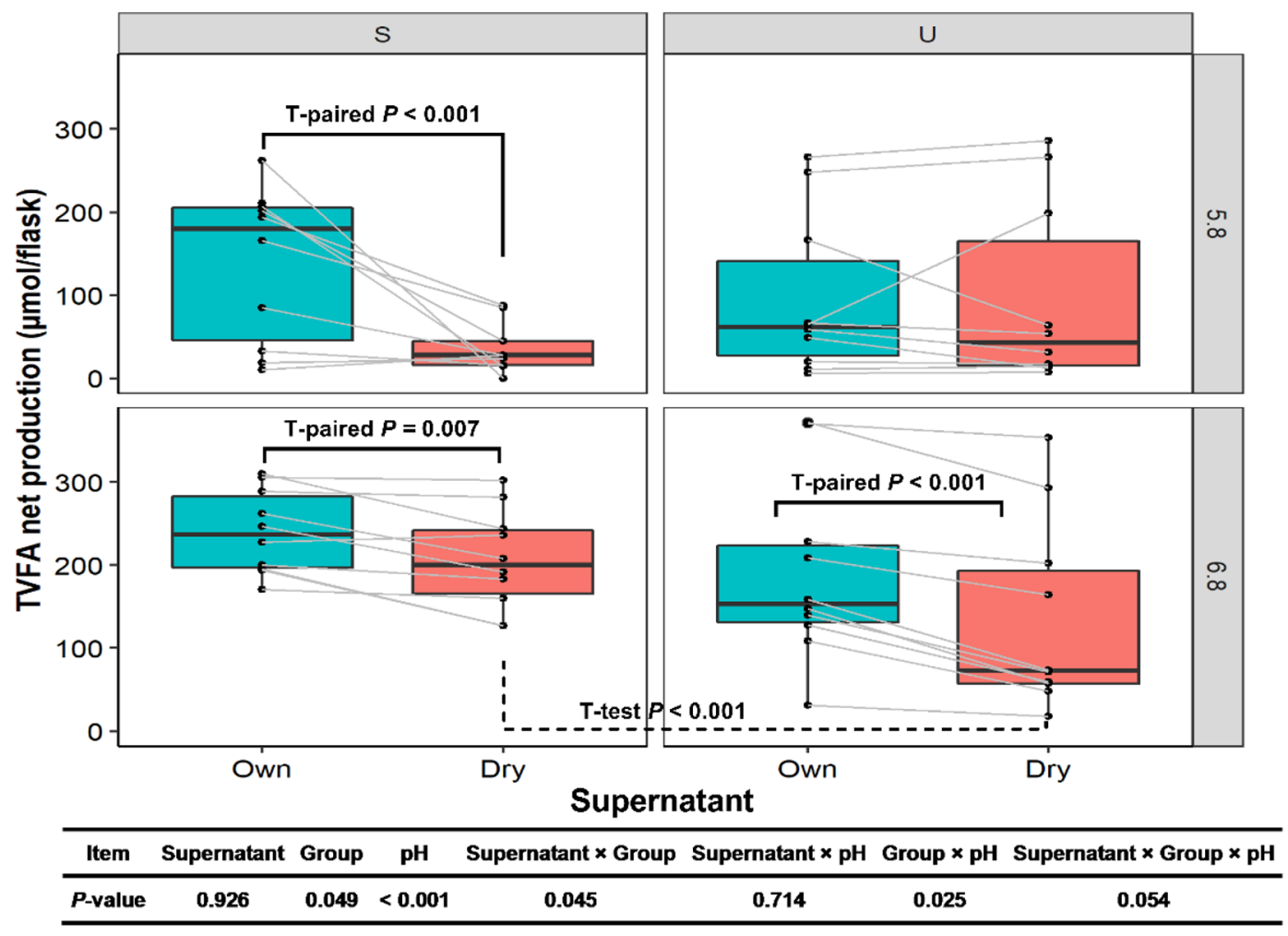

Figure 5. Net in vitro total volatile fatty acid (TVFA) production by microbes from cows classified as susceptible (S, n $=10)$ or unsusceptible $(\mathrm{U}, \mathrm{n}=10)$ to SARA during the first $3 \mathrm{wk}$ postpartum. In vitro incubation was performed either with dry cows' or with lactating cows' own sterile supernatant at $\mathrm{pH} 5.8$ or 6.8 . As significant 2- and 3-way interactions occurred, treatments were compared within pH conditions. When significant, differences between supernatants (Own vs. Dry, paired $t$-test within inoculum) and inoculum (S vs. U, unpaired $t$-test within supernatant) are indicated with solid and dotted lines, respectively. The upper and lower edges of boxes represent the upper and lower quartiles of the interquartile range, and the midline is the median. The whiskers show the upper and lower values within 1.5 times the interquartile range from the upper and lower quartiles. The dots represent individual values.

caceae were observed in the rumen bacterial community of S cows. Starch-degrading bacteria have often been reported to be included in these genera and families (Strobel, 1992; Klieve et al., 2007; Mu et al., 2021). In line with this, McCann et al. (2016) also found an increase in the abundance of the family Prevotellaceae and the genus Prevotella in cows with rumen $\mathrm{pH}$ below 5.6 for more than $3 \mathrm{~h}$ under a SARA challenge including 1-d feed restriction followed by increased concentrate intake. Nevertheless, in our case, differences between groups were not provoked by changes in total DMI or intake of roughage or concentrate, nor by differences in diurnal intake pattern. In addition to starch degraders, known lactate producers, such as Streptococcus, Sharpea, and Succinivibrionaceae_UCG-001 were higher in $\mathrm{S}$ cows compared with $\mathrm{U}$ cows, which could have been expected given their tolerance to low $\mathrm{pH}$, probably linked to the enhanced activity of lactate dehydrogenase in bacterial cells of these genera under low-pH circumstances (Asanuma and Hino, 1997; Kamke et al., 2016; Dai et al., 2020). Increased abundance of lactateproducing bacteria in SARA-susceptible cows also has been reported in previous studies in which increased abundance of uncultured Streptococcaceae and Streptococcus bovis were observed in cows experiencing a reticular $\mathrm{pH}$ below 6.0 (equivalent to rumen $\mathrm{pH}$ below 5.8 ) of at least $90 \mathrm{~min} / \mathrm{d}$, with a group mean of 7.54 $\mathrm{h} / \mathrm{d}$ (Dewanckele et al., 2019), as well as in cows with mean time of rumen $\mathrm{pH}$ below 5.6 of at least $337 \mathrm{~min} / \mathrm{d}$ (Khafipour et al., 2009a). However, higher abundance of the lactate utilizers (i.e., Megasphaera) in S cows was not observed in our study, whereas such difference was reported by Dewanckele et al. (2019). As the higher relative abundance of Megasphaera in SARA-susceptible cows was observed during both the low- and the highstarch periods in the study by Dewanckele et al. (2019), this seemed to be an animal characteristic rather than directly related to the rumen $\mathrm{pH}$ conditions. However, in the study by Khafipour et al. (2009a), Escherichia coli, associated with endotoxin release, also increased in the severe-SARA cows (rumen $\mathrm{pH}$ below 5.6 for at least $337 \mathrm{~min} / \mathrm{d}$ ) under a $60 \%$ grain-induced SARA challenge. In our study $\mathrm{U}$ and $\mathrm{S}$ cows did not differ in abundance of the genus Escherichia, to which this 
species belongs. However, only 4 out of the $10 \mathrm{~S}$ cows suffered from SARA over the entire 3-wk postpartum period in the current study. Within these 4 cows, only in 1 was Escherichia-Shigella detected, with a relative abundance of $0.073 \%$. Similarly, in the mild-SARA cows (rumen $\mathrm{pH}$ below 5.6 for at least $217 \mathrm{~min} / \mathrm{d}$ ) reported by Khafipour et al. (2009a), no increase in Escherichia coli has been observed. Accordingly, Escherichia coli proliferation seems an indication of harsh rumen $\mathrm{pH}$ conditions under a SARA challenge. Hence, in terms of changes in bacterial families and genera with starch degraders and lactate producers, inter-animal variation of periparturient cows under practical management seems comparable to changes observed in cows under SARA challenges. However, Escherichia coli seems an indicator for harsher $\mathrm{pH}$ conditions.

Noninvasive oral samples have been reported as an attractive alternative to sampling of the ruminal bacterial community at a large scale (Kittelmann et al., 2015; Tapio et al., 2016). Accordingly, we hypothesized that the bacterial genera, discriminating between $\mathrm{S}$ and $\mathrm{U}$ cows, would be the same in rumen and saliva samples. However, the top 20 most predictive genera in the random forest classification of S and U cows showed only 3 common genera in both sample types: uncultured Erysipelotrichaceae, Prevotella, and Anaerovibrio. Strikingly, the genus Streptococcus was one of the dominant genera in the saliva samples, although not within the top 10 of most abundant rumen genera. This may be related to the difficulty of manually removing some of the oral ASV from this genus. As such, this also could have affected the classification accuracy. As a result, in the current study, the bacterial community in saliva seemed less accurate than the rumen bacteria in classifying S and U cows $(62.5 \%$ vs. $75 \%$ accuracy, respectively). Obviously, these results should be interpreted with caution, as the number of observations included in the current study is relatively limited, particularly for the random forest classification methodology. Nevertheless, in former studies applying this technique to classify animals according to their health status or diets based on their gastrointestinal microbiota, the number

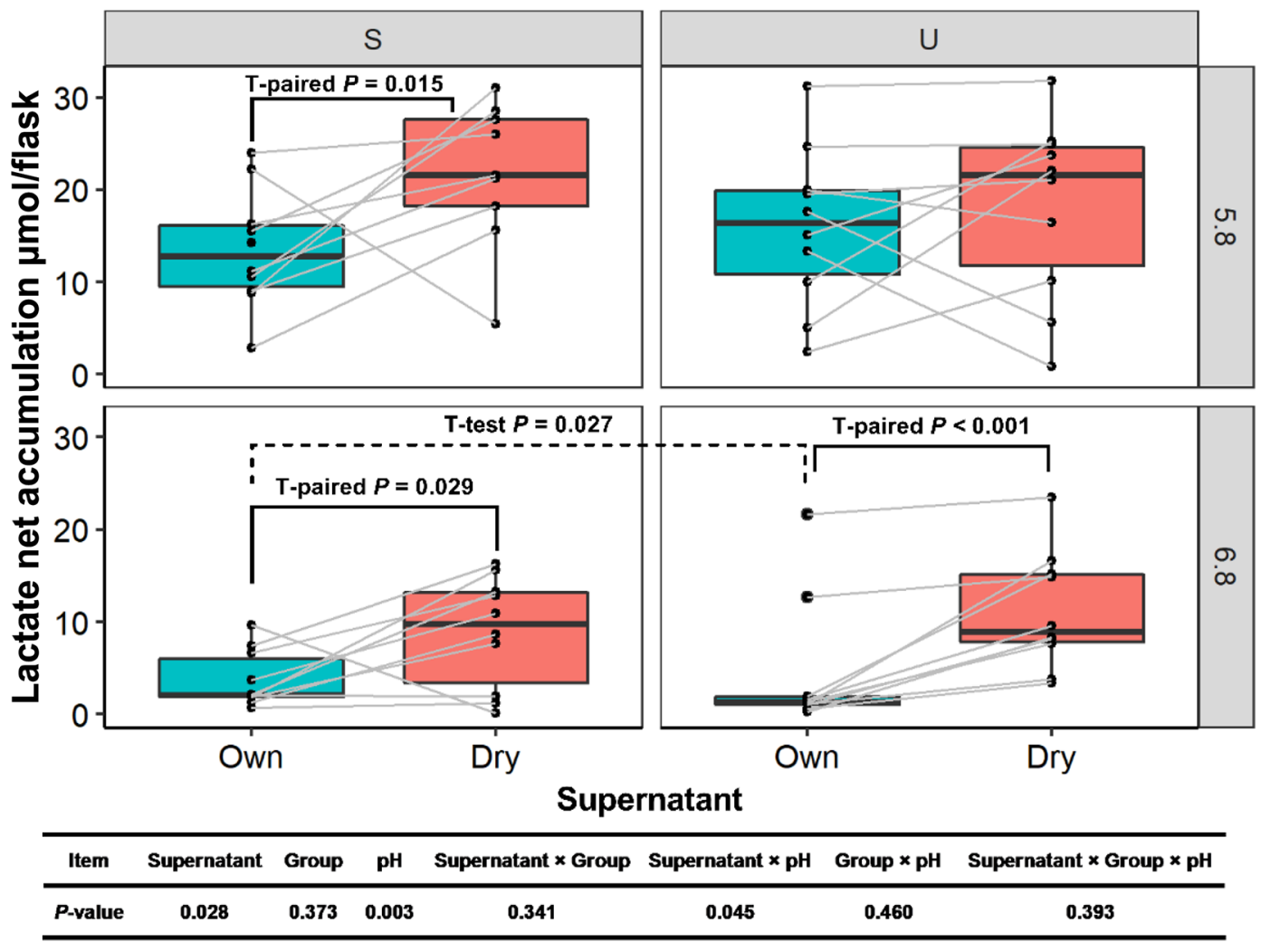

Figure 6. Net in vitro lactate accumulation by microbes from cows classified as susceptible $(\mathrm{S}, \mathrm{n}=10)$ or unsusceptible $(\mathrm{U}, \mathrm{n}=10)$ to $\mathrm{SARA}$ during the first 3 wk postpartum. In vitro incubation was performed either with dry cows' or with lactating cows' own sterile supernatant at pH 5.8 or 6.8. As significant 2-way interaction occurred, treatments were compared within pH conditions. As significant 2- and 3-way interactions occurred, treatments were compared within $\mathrm{pH}$ conditions. When significant, differences between supernatants (Own vs. Dry, paired $t$-test within inoculum) and inoculum ( $\mathrm{S}$ vs. $\mathrm{U}$, unpaired $t$-test within supernatant) are indicated with solid and dotted lines, respectively. The upper and lower edges of boxes represent the upper and lower quartiles of the interquartile range, and the midline is the median. The whiskers show the upper and lower values within 1.5 times the interquartile range from the upper and lower quartiles. The dots represent individual values. 
of animals included was not always higher $(16,12$, and 39 in the studies by Xin et al., 2021; Liu et al., 2020; and Ma et al., 2020, respectively).

As microbiota carry out various metabolic functions, variations in the bacterial community structure in cows differing in reticular $\mathrm{pH}$ profile might affect the functionality of microorganisms to cope with different disturbances during transition. In the current study, the functionality of the rumen microbiota was evaluated in vitro through exposure of the microbial inoculum of $\mathrm{S}$ and $\mathrm{U}$ cows to an anaerobic buffer at different $\mathrm{pH}$ (5.8 and 6.8) and in the presence of sterile supernatant of their own and of dry cows' rumen fluid. Ruminal $\mathrm{pH}$ is a critical factor affecting and potentially disturbing metabolic activity of rumen microbiota (Chen et al., 2019; Khiaosa-ard et al., 2020). At low pH, in situ fiber degradation and overall rumen fermentation were reduced by alteration of metabolic pathways associated with glycolysis and pyruvate fermentation (Pourazad et al., 2017; Li et al., 2021). In the current study as well as in the study by Khiaosa-ard et al. (2020), this reduced fermentation was also observed when exposing rumen inoculum to lower $\mathrm{pH}$ conditions in vitro. Nevertheless, the reduction in TVFA concentration (i.e., $7.8 \mathrm{mmol} / \mathrm{L}$, from 92.5 to $84.7 \mathrm{mmol} / \mathrm{L}$ ) from high-pH to low-pH conditions in the study of Khiaosa-ard et al. (2020) was less severe than the reduction observed in the current study. This may be related to the milder acidotic conditions ( $\mathrm{pH} 6.0$ vs. a standard $\mathrm{pH}$ of 6.6 ) in Khiaosa-ard et al. (2020) compared with the stronger $\mathrm{pH}$ reduction ( $\mathrm{pH} 6.8$ to $\mathrm{pH} 5.8$ ) induced in the current study. Further, exposure to dry cows' rumen fluid was chosen because the diet of cows in the far-off period differentiates most from that of cows in early lactation. As such, it could be hypothesized that exposure to this type of supernatant requires more adaptive abilities of the ruminal microbes, as compared with exposure to their own supernatant. When exposed to no stressor (pH of 6.8 and own supernatant) or one stressor (i.e., either $\mathrm{pH}$ of 5.8 with own supernatant or dry cows' supernatant at $\mathrm{pH}$ 6.8), microbial inoculum collected from $\mathrm{S}$ cows produced more TVFA than microbes originating from U cows. Previous in vivo studies have also reported an increase of the TVFA concentration in the rumen of SARA-susceptible steers compared with unsusceptible steers in an 85\%-grain SARA challenge (Chen et al., 2012; Schlau et al., 2012). Obviously, in vivo, final TVFA concentrations are determined by the balance between the amount of TVFA produced during rumen fermentation and their removal and neutralization. Nevertheless, Gao and Oba (2016) suggested no difference in TVFA absorption rate between susceptible and unsusceptible cows, which would imply that higher ruminal TVFA concentrations could have been particularly provoked by a higher TVFA production.

Interestingly, when exposed to a combination of stressors, such as low pH (5.8) and external supernatant (dry cows' sterile supernatant), microbes obtained from U cows were capable of maintaining TVFA production at the level of incubations with their own sterile supernatant at $\mathrm{pH} 5.8$ without increase in lactate accumulation. By contrast, TVFA production was completely stopped and lactate accumulation was highest in $\mathrm{pH}$ 5.8 incubations with external supernatant and microbes collected from $\mathrm{S}$ cows. The reduced resilience of SARA microbiota to a combination of disturbances was also observed by Rabaza et al. (2020): in their study, 20 animals suffering from SARA before the experimental period were exposed to a variable length of feed withdrawal $(0,12,24$, or $36 \mathrm{~h})$ followed by a resumption of the feed supply. Total rumen VFA concentrations decreased, and lactate accumulation increased with increasing length of feed withdrawal. Although, in that study, no comparison was made with animals that did not suffer from SARA before feed withdrawal, nevertheless, both their study and ours could suggest an association between the inter-animal variation in SARA susceptibility and the capacity of their ruminal microorganisms to adapt to external stressors.

\section{CONCLUSIONS}

Variation in reticular $\mathrm{pH}$ was shown among cows housed under the same conditions during a 3 -wk postpartum period. Cows highly susceptible to SARA (S group), experiencing low $\mathrm{pH}$ for a longer period, differed in ruminal bacterial copy numbers and composition from those that hardly experienced any $\mathrm{pH}$ drop below 6.0 during this postpartum period (U cows). More specifically, the relative abundance of lactate producers, such as Streptococcus, Sharpea, and Succinivibrionaceae_UCG-001, as well as starch degraders of the genera Prevotellaceae_YAB2003, Ruminococcus, and Ruminococcaceae_UCG-001, were increased in the rumen bacteria of S cows. In contrast, the genera Lachnospiraceae_ND3007 and Oscillospiraceae_V9D2013 were more abundant in rumen samples from $U$ cows. Additionally, pH-associated inter-animal differences were observed in the salivary bacteria, but common differences in ruminal and salivary bacterial genera were limited. Furthermore, inter-animal reticular $\mathrm{pH}$ differences were reflected in changes in the fermentative activity of microorganisms upon in vitro exposure to $\mathrm{pH}$ of 6.8 or 5.8 and sterile supernatant of their own or dry cows' rumen fluid. The $\mathrm{S}$ inoculum produced more TVFA, except at low $\mathrm{pH}$ with the dry cows' 
supernatant, where VFA production was completely impaired and lactate accumulation was highest. Taken together, SARA-susceptible cows showed differences in the rumen microbial community, salivary bacterial community, and ruminal microbial fermentative capacity in vitro.

\section{ACKNOWLEDGMENTS}

We gratefully acknowledge the financial support of Flanders Innovation \& Entrepreneurship (VLAIO; Brussels, Belgium; LA170830) and the European Union's Horizon 2020 research and innovation program under grant agreement 101000213-HoloRuminant. The $\mathrm{PhD}$ research of Hong Yang and Xiaoping Jing were supported by the Chinese Scholarship Council (CSC; Beijing, China); the PhD research of Stijn Heirbaut was funded by a $\mathrm{PhD}$ grant from the Special Research Fund of the Ghent University (Bijzonder Onderzoeksfonds, BOF; Ghent, Belgium). The authors gratefully acknowledge the staff of the Animal Sciences Unit, Flanders Research Institute for Agriculture (Melle, Belgium) for their help during these experiments. We also thank Charlotte Melis (Laboratory for Animal Nutrition and Animal Product Quality, Department of Animal Sciences and Aquatic Ecology, Ghent University) for help with sampling. The authors have not stated any conflicts of interest.

\section{REFERENCES}

Asanuma, N., and T. Hino. 1997. Tolerance to low pH and lactate production in rumen bacteria. Anim. Sci. Technol. 68:367-376. https: //doi.org/10.2508/chikusan.68.367.

Bates, D., M. Mächler, B. Bolker, and S. Walker. 2015. Fitting linear mixed-effects models using lme4. J. Stat. Softw. 67:1-48. https:// doi.org/10.18637/jss.v067.i01.

Beauchemin, K. A., W. Z. Yang, and L. M. Rode. 2003. Effects of particle size of alfalfa-based dairy cow diets on chewing activity, ruminal fermentation, and milk production. J. Dairy Sci. 86:630-643. https://doi.org/10.3168/jds.S0022-0302(03)73641-8.

Bokulich, N. A., B. D. Kaehler, J. R. Rideout, M. Dillon, E. Bolyen, R. Knight, G. A. Huttley, and J. Gregory Caporaso. 2018. Optimizing taxonomic classification of marker-gene amplicon sequences with QIIME 2's q2-feature-classifier plugin. Microbiome 6:90. https:// doi.org/10.1186/s40168-018-0470-z.

Bolyen, E., J. R. Rideout, M. R. Dillon, N. A. Bokulich, C. C. Abnet, G. A. Al-Ghalith, H. Alexander, E. J. Alm, M. Arumugam, F Asnicar, Y. Bai, J. E. Bisanz, K. Bittinger, A. Brejnrod, C. J. Brislawn, C. T. Brown, B. J. Callahan, A. M. Caraballo-Rodríguez, J. Chase, E. K. Cope, R. Da Silva, C. Diener, P. C. Dorrestein, G. M. Douglas, D. M. Durall, C. Duvallet, C. F. Edwardson, M. Ernst, M. Estaki, J. Fouquier, J. M. Gauglitz, S. M. Gibbons, D. L. Gibson, A. Gonzalez, K. Gorlick, J. Guo, B. Hillmann, S. Holmes, H. Holste, C. Huttenhower, G. A. Huttley, S. Janssen, A. K. Jarmusch, L. Jiang, B. D. Kaehler, K. B. Kang, C. R. Keefe, P. Keim, S. T. Kelley, D. Knights, I. Koester, T. Kosciolek, J. Kreps, M. G. I. Langille, J. Lee, R. Ley, Y.-X. Liu, E. Loftfield, C. Lozupone, M. Maher, C. Marotz, B. D. Martin, D. McDonald, L. J. McIver, A. V. Melnik, J. L. Metcalf, S. C. Morgan, J. T. Morton, A. T. Naimey, J. A. Navas-Molina, L. F. Nothias, S. B. Orchanian,
T. Pearson, S. L. Peoples, D. Petras, M. L. Preuss, E. Pruesse, L. B. Rasmussen, A. Rivers, M. S. Robeson II, P. Rosenthal, N. Segata, M. Shaffer, A. Shiffer, R. Sinha, S. J. Song, J. R. Spear, A. D. Swafford, L. R. Thompson, P. J. Torres, P. Trinh, A. Tripathi, P. J. Turnbaugh, S. Ul-Hasan, J. J. J. van der Hooft, F. Vargas, Y. Vázquez-Baeza, E. Vogtmann, M. von Hippel, W. Walters, Y. Wan, M. Wang, J. Warren, K. C. Weber, C. H. D. Williamson, A. D. Willis, Z. Z. Xu, J. R. Zaneveld, Y. Zhang, Q. Zhu, R. Knight, and J. G. Caporaso. 2019. Reproducible, interactive, scalable and extensible microbiome data science using QIIME 2. Nat. Biotechnol. 37:852-857. https://doi.org/10.1038/s41587-019-0209-9.

Callahan, B. J., P. J. McMurdie, M. J. Rosen, A. W. Han, A. J. A. Johnson, and S. P. Holmes. 2016. DADA2: High-resolution sample inference from Illumina amplicon data. Nat. Methods 13:581-583. https://doi.org/10.1038/nmeth.3869.

Carberry, C. A., D. A. Kenny, S. Han, M. S. McCabe, and S. M. Waters. 2012. Effect of phenotypic residual feed intake and dietary forage content on the rumen microbial community of beef cattle. Appl. Environ. Microbiol. 78:4949-4958. https://doi.org/10.1128/ AEM.07759-11.

Chen, L., Y. Shen, C. Wang, L. Ding, F. Zhao, M. Wang, J. Fu, and H. Wang. 2019. Megasphaera elsdenii lactate degradation pattern shifts in rumen acidosis models. Front. Microbiol. 10:162. https:// doi.org/10.3389/fmicb.2019.00162.

Chen, Y., M. Oba, and L. L. Guan. 2012. Variation of bacterial communities and expression of Toll-like receptor genes in the rumen of steers differing in susceptibility to subacute ruminal acidosis. Vet. Microbiol. 159:451-459. https://doi.org/10.1016/j.vetmic.2012.04 .032 .

Conway, E. J. 1957. Microdiffusion Analysis and Volumetric Error. 4th ed. Crosby Lockwood.

Dai, X., T. J. Hackmann, R. R. Lobo, and A. P. Faciola. 2020. Lipopolysaccharide stimulates the growth of bacteria that contribute to ruminal acidosis. Appl. Environ. Microbiol. 86:e02193-19. https: //doi.org/10.1128/AEM.02193-19.

De Mol, R. M., R. M. A. Goselink, J. W. Van Riel, H. M. Knijn, and A. T. M. Van Knegsel. 2016. The relation between eating time and feed intake of dairy cows. Pages 387-392 in Precision Dairy Farming 2016. Wageningen Academic Publishers. https://doi.org/ 10.3920/978-90-8686-829-2.

Denman, S. E., and C. S. McSweeney. 2006. Development of a realtime PCR assay for monitoring anaerobic fungal and cellulolytic bacterial populations within the rumen. FEMS Microbiol. Ecol. 58:572-582. https://doi.org/10.1111/j.1574-6941.2006.00190.x.

Denman, S. E., N. W. Tomkins, and C. S. McSweeney. 2007. Quantitation and diversity analysis of ruminal methanogenic populations in response to the antimethanogenic compound bromochloromethane. FEMS Microbiol. Ecol. 62:313-322. https://doi.org/10.1111/ j.1574-6941.2007.00394.x.

Dewanckele, L., J. Jeyanathan, B. Vlaeminck, and V. Fievez. 2020. Identifying and exploring biohydrogenating rumen bacteria with emphasis on pathways including trans-10 intermediates. BMC Microbiol. 20:198. https://doi.org/10.1186/s12866-020-01876-7.

Dewanckele, L., L. Jing, B. Stefańska, B. Vlaeminck, J. Jeyanathan, W. M. Van Straalen, A. Koopmans, and V. Fievez. 2019. Distinct blood and milk 18-carbon fatty acid proportions and buccal bacterial populations in dairy cows differing in reticulorumen $\mathrm{pH}$ response to dietary supplementation of rapidly fermentable carbohydrates. J. Dairy Sci. 102:4025-4040. https://doi.org/10.3168/jds .2018-15823.

Edwards, J. E., A. H. Kingston-Smith, H. R. Jimenez, S. A. Huws, K. P. Skøt, G. W. Griffith, N. R. McEwan, and M. K. Theodorou. 2008. Dynamics of initial colonization of nonconserved perennial ryegrass by anaerobic fungi in the bovine rumen. FEMS Microbiol. Ecol. 66:537-545. https://doi.org/10.1111/j.1574-6941.2008.00563 .x.

Fonty, G., P. Raibaud, and P. Gouet. 1993. Manipulation of the gut microflora: experimental approach in animals. Proc. Nutr. Soc. 52:345-356. https://doi.org/10.1079/PNS19930070.

Fox, J., and S. Weisberg. 2019. An R Companion to Applied Regression. 3rd ed. Sage. 
Gao, X., and M. Oba. 2016. Characteristics of dairy cows with a greater or lower risk of subacute ruminal acidosis: Volatile fatty acid absorption, rumen digestion, and expression of genes in rumen epithelial cells. J. Dairy Sci. 99:8733-8745. https://doi.org/10.3168/ jds.2016-11570.

Geishauser, T., N. Linhart, A. Neidl, and A. Reimann. 2012. Factors associated with ruminal $\mathrm{pH}$ at herd level. J. Dairy Sci. 95:45564567. https://doi.org/10.3168/jds.2012-5380.

Grummer, R. R. 1995. Impact of changes in organic nutrient metabolism on feeding the transition dairy cow. J. Anim. Sci. 73:2820. https://doi.org/10.2527/1995.7392820x.

Hayirli, A., R. R. Grummer, E. V. Nordheim, and P. M. Crump. 2003. Models for predicting dry matter intake of Holsteins during the prefresh transition period. J. Dairy Sci. 86:1771-1779. https://doi .org/10.3168/jds.S0022-0302(03)73762-X.

Hook, S. E., M. Steele, K. Northwood, A.-D. Wright, and B. McBride. 2011. Impact of high-concentrate feeding and low ruminal $\mathrm{pH}$ on methanogens and protozoa in the rumen of dairy cows. Microb. Ecol. 62:94-105. https://doi.org/10.1007/s00248-011-9881-0.

Humer, E., J. R. Aschenbach, V. Neubauer, I. Kröger, R. Khiaosa-ard, W. Baumgartner, and Q. Zebeli. 2018. Signals for identifying cows at risk of subacute ruminal acidosis in dairy veterinary practice. J. Anim. Physiol. Anim. Nutr. (Berl.) 102:380-392. https://doi.org/ 10.1111/jpn.12850.

Jing, L., L. Dewanckele, B. Vlaeminck, W. M. Van Straalen, A. Koopmans, and V. Fievez. 2018. Susceptibility of dairy cows to subacute ruminal acidosis is reflected in milk fatty acid proportions, with $\mathrm{C} 18: 1$ trans-10 as primary and $\mathrm{C} 15: 0$ and C18:1 trans-11 as secondary indicators. J. Dairy Sci. 101:9827-9840. https://doi .org/10.3168/jds.2018-14903.

Kamke, J., S. Kittelmann, P. Soni, Y. Li, M. Tavendale, S. Ganesh, P. H. Janssen, W. Shi, J. Froula, E. M. Rubin, and G. T. Attwood. 2016. Rumen metagenome and metatranscriptome analyses of low methane yield sheep reveals a Sharpea-enriched microbiome characterised by lactic acid formation and utilisation. Microbiome 4:56. https://doi.org/10.1186/s40168-016-0201-2.

Khafipour, E., D. O. Krause, and J. C. Plaizier. 2009b. A grain-based subacute ruminal acidosis challenge causes translocation of lipopolysaccharide and triggers inflammation. J. Dairy Sci. 92:10601070. https://doi.org/10.3168/jds.2008-1389.

Khafipour, E., S. Li, J. C. Plaizier, and D. O. Krause. 2009a. Rumen microbiome composition determined using two nutritional models of subacute ruminal acidosis. Appl. Environ. Microbiol. 75:71157124. https://doi.org/10.1128/AEM.00739-09.

Khiaosa-ard, R., M. Mahmood, F. Lerch, F. P. Traintinger, R. M. Petri, M. Münnich, and Q. Zebeli. 2020. Physicochemical stressors and mixed alkaloid supplementation modulate ruminal microbiota and fermentation. Anaerobe 65:102263. https://doi.org/10.1016/j anaerobe.2020.102263.

Khiaosa-ard, R., P. Pourazad, S. Aditya, E. Humer, and Q. Zebeli. 2018. Factors related to variation in the susceptibility to subacute ruminal acidosis in early lactating Simmental cows fed the same grain-rich diet. Anim. Feed Sci. Techn. 238:111-122. https://doi .org/10.1016/j.anifeedsci.2018.02.005.

Khorrami, B., R. Khiaosa-ard, and Q. Zebeli. 2021. Models to predict the risk of subacute ruminal acidosis in dairy cows based on dietary and cow factors: A meta-analysis. J. Dairy Sci. 104:77617780. https://doi.org/10.3168/jds.2020-19890.

Kittelmann, S., M. R. Kirk, A. Jonker, A. McCulloch, and P. H. Janssen. 2015. Buccal swabbing as a noninvasive method to determine bacterial, archaeal, and eukaryotic microbial community structures in the rumen. Appl. Environ. Microbiol. 81:7470-7483. https: //doi.org/10.1128/AEM.02385-15.

Klieve, A. V., M. N. O'Leary, L. McMillen, and D. Ouwerkerk. 2007. Ruminococcus bromii, identification and isolation as a dominant community member in the rumen of cattle fed a barley diet. J. Appl. Microbiol. 103:2065-2073. https://doi.org/10.1111/j.1365 $-2672.2007 .03492 . x$

Klindworth, A., E. Pruesse, T. Schweer, J. Peplies, C. Quast, M. Horn, and F. O. Glöckner. 2013. Evaluation of general 16S ribosomal RNA gene PCR primers for classical and next-generation sequenc- ing-based diversity studies. Nucleic Acids Res. 41:e1. https://doi .org $/ 10.1093 /$ nar $/$ gks808.

Kuhn, M. 2008. Building predictive models in R using the caret package. J. Stat. Softw. 28:1-26. https://doi.org/10.18637/jss.v028.i05.

Kunz, I. G. Z., K. J. Reed, J. L. Metcalf, D. M. Hassel, R. J. Coleman, T. M. Hess, and S. J. Coleman. 2019. Equine fecal microbiota changes associated with anthelmintic administration. J. Equine Vet. Sci. 77:98-106. https://doi.org/10.1016/j.jevs.2019.01.018.

Li, M. M., R. R. White, L. L. Guan, L. Harthan, and M. D. Hanigan. 2021. Metatranscriptomic analyses reveal ruminal $\mathrm{pH}$ regulates fiber degradation and fermentation by shifting the microbial community and gene expression of carbohydrate-active enzymes. Anim. Microbiome 3:32. https://doi.org/10.1186/s42523-021-00092-6.

Liaw, A., and M. Wiener. 2002. Classification and regression by randomForest. $\mathrm{R}$ News 2:18-22. https://cran.r-project.org/doc/ Rnews/Rnews_2002-3.pdf.

Liu, J., F. Liu, W. Cai, C. Jia, Y. Bai, Y. He, W. Zhu, R. W. Li, and J. Song. 2020. Diet-induced changes in bacterial communities in the jejunum and their associations with bile acids in Angus beef cattle. Anim. Microbiome 2:33. https://doi.org/10.1186/s42523 $-020-00051-7$.

Long, R. A., and F. Azam. 2001. Antagonistic interactions among marine pelagic bacteria. Appl. Environ. Microbiol. 67:4975-4983. https://doi.org/10.1128/AEM.67.11.4975-4983.2001.

Ma, T., C. Villot, D. Renaud, A. Skidmore, E. Chevaux, M. Steele, and L. L. Guan. 2020. Linking perturbations to temporal changes in diversity, stability, and compositions of neonatal calf gut microbiota: Prediction of diarrhea. ISME J. 14:2223-2235. https://doi .org/10.1038/s41396-020-0678-3.

Mandal, S., W. Van Treuren, R. A. White, M. Eggesbø, R. Knight, and S. D. Peddada. 2015. Analysis of composition of microbiomes: A novel method for studying microbial composition. Microb. Ecol. Health Dis. 26:27663. https://doi.org/10.3402/mehd.v26.27663.

McCann, J. C., S. Luan, F. C. Cardoso, H. Derakhshani, E. Khafipour, and J. J. Loor. 2016. Induction of subacute ruminal acidosis affects the ruminal microbiome and epithelium. Front. Microbiol. 7:701. https://doi.org/10.3389/fmicb.2016.00701.

Mensching, A., K. Bünemann, U. Meyer, D. von Soosten, J. Hummel, A. O. Schmitt, A. R. Sharifi, and S. Dänicke. 2020. Modeling of reticular and ventral ruminal $\mathrm{pH}$ of lactating dairy cows using ingestion and rumination behavior. J. Dairy Sci. 103:7260-7275. https://doi.org/10.3168/jds.2020-18195.

Mohammed, R., D. M. Stevenson, P. J. Weimer, G. B. Penner, and K. A. Beauchemin. 2012. Individual animal variability in ruminal bacterial communities and ruminal acidosis in primiparous Holstein cows during the periparturient period. J. Dairy Sci. 95:67166730. https://doi.org/10.3168/jds.2012-5772.

Mu, Y. Y., W. P. Qi, T. Zhang, J. Y. Zhang, and S. Y. Mao. 2021. Gene function adjustment for carbohydrate metabolism and enrichment of rumen microbiota with antibiotic resistance genes during subacute rumen acidosis induced by a high-grain diet in lactating dairy cows. J. Dairy Sci. 104:2087-2105. https://doi.org/ 10.3168/jds.2020-19118.

Neubauer, V., E. Humer, I. Kröger, T. Braid, M. Wagner, and Q. Zebeli. 2018. Differences between $\mathrm{pH}$ of indwelling sensors and the $\mathrm{pH}$ of fluid and solid phase in the rumen of dairy cows fed varying concentrate levels. J. Anim. Physiol. Anim. Nutr. (Berl.) 102:343-349. https://doi.org/10.1111/jpn.12675.

Plaizier, J. C., M. Danesh Mesgaran, H. Derakhshani, H. Golder, E. Khafipour, J. L. Kleen, I. Lean, J. Loor, G. Penner, and Q. Zebeli. 2018. Review: Enhancing gastrointestinal health in dairy cows. Animal 12:s399-s418. https://doi.org/10.1017/S1751731118001921.

Plaizier, J. C., D. O. Krause, G. N. Gozho, and B. W. McBride. 2008. Subacute ruminal acidosis in dairy cows: The physiological causes, incidence and consequences. Vet. J. 176:21-31. https://doi.org/10 $.1016 / j . t v j 1.2007 .12 .016$.

Pourazad, P., R. Khiaosa-ard, B. U. Metzler-Zebeli, F. Klevenhusen, and Q. Zebeli. 2017. Restoration of in situ fiber degradation and the role of fibrolytic microbes and ruminal $\mathrm{pH}$ in cows fed grainrich diets transiently or continuously. Animal 11:2193-2202. https: //doi.org/10.1017/S1751731117001112. 
R Core Team. 2020. R: A language and environment for statistical computing. R Foundation for Statistical Computing. https://www .R-project.org/.

Rabaza, A., G. Banchero, C. Cajarville, P. Zunino, A. Britos, J. L. Repetto, and M. Fraga. 2020. Effects of feed withdrawal duration on animal behaviour, rumen microbiota and blood chemistry in feedlot cattle: Implications for rumen acidosis. Animal 14:66-77. https://doi.org/10.1017/S1751731119001538.

Schlau, N., L. L. Guan, and M. Oba. 2012. The relationship between rumen acidosis resistance and expression of genes involved in regulation of intracellular $\mathrm{pH}$ and butyrate metabolism of ruminal epithelial cells in steers. J. Dairy Sci. 95:5866-5875. https://doi.org/ 10.3168/jds.2011-5167.

Shaani, Y., T. Zehavi, S. Eyal, J. Miron, and I. Mizrahi. 2018. Microbiome niche modification drives diurnal rumen community assembly, overpowering individual variability and diet effects. ISME J. 12:2446-2457. https://doi.org/10.1038/s41396-018-0203-0.

Stauder, A., E. Humer, V. Neubauer, N. Reisinger, A. Kaltenegger, and Q. Zebeli. 2020. Distinct responses in feed sorting, chewing behavior, and ruminal acidosis risk between primiparous and multiparous Simmental cows fed diets differing in forage and starch levels. J. Dairy Sci. 103:8467-8481. https://doi.org/10.3168/jds .2019-17760.

Strobel, H. J. 1992. Vitamin B12-dependent propionate production by the ruminal bacterium Prevotella ruminicola 23. Appl. Environ. Microbiol. 58:2331-2333. https://doi.org/10.1128/aem.58.7.2331 $-2333.1992$

Tamminga, S., W. Van Straalen, A. Subnel, R. Meijer, A. Steg, C. Wever, and M. Blok. 1994. The Dutch protein evaluation system: Rhe DVE/OEB-system. Livest. Prod. Sci. 40:139-155. https://doi .org/10.1016/0301-6226(94)90043-4.

Tapio, I., K. J. Shingfield, N. McKain, A. Bonin, D. Fischer, A. R. Bayat, J. Vilkki, P. Taberlet, T. J. Snelling, and R. J. Wallace. 2016 Oral samples as non-invasive proxies for assessing the composition of the rumen microbial community. PLoS One 11:e0151220. https: //doi.org/10.1371/journal.pone.0151220.

Vallejo-Timarán, D., J. Reyes-Vélez, J. VanLeeuwen, J. MaldonadoEstrada, and J. Astaiza-Martínez. 2020. Incidence and effects of subacute ruminal acidosis and subclinical ketosis with respect to postpartum anestrus in grazing dairy cows. Heliyon 6:e03712. https://doi.org/10.1016/j.heliyon.2020.e03712.

Van Es, A. J. H. 1975. Feed evaluation for dairy cows. Livest. Prod. Sci. 2:95-107. https://doi.org/10.1016/0301-6226(75)90029-9.

Wetzels, S. U., E. Mann, P. Pourazad, M. Qumar, B. Pinior, B. U. Metzler-Zebeli, M. Wagner, S. Schmitz-Esser, and Q. Zebeli. 2017. Epimural bacterial community structure in the rumen of Holstein cows with different responses to a long-term subacute ruminal acidosis diet challenge. J. Dairy Sci. 100:1829-1844. https://doi.org/ 10.3168/jds.2016-11620

Xin, H., T. Ma, Y. Xu, G. Chen, Y. Chen, C. Villot, D. L. Renaud, M. A. Steele, and L. L. Guan. 2021. Characterization of fecal branched-chain fatty acid profiles and their associations with fecal microbiota in diarrheic and healthy dairy calves. J. Dairy Sci. 104:2290-2301. https://doi.org/10.3168/jds.2020-18825.

Yang, H., S. Heirbaut, J. Jeyanathan, X. Jing, N. De Neve, L. Vandaele, and V. Fievez. 2022. Supplemental tables and figures.docx. figshare. Figure. https://doi.org/10.6084/m9.figshare.19158098.v1.

Yu, Z., and M. Morrison. 2004. Improved extraction of PCR-quality community DNA from digesta and fecal samples. Biotechniques 36:808-812. https://doi.org/10.2144/04365ST04.

Zebeli, Q., J. Dijkstra, M. Tafaj, H. Steingass, B. N. Ametaj, and W. Drochner. 2008. Modeling the adequacy of dietary fiber in dairy cows based on the responses of ruminal $\mathrm{pH}$ and milk fat production to composition of the diet. J. Dairy Sci. 91:2046-2066. https: //doi.org/10.3168/jds.2007-0572.

\section{ORCIDS}

H. Yang (®) https://orcid.org/0000-0001-7211-6406

S. Heirbaut $\odot$ https://orcid.org/0000-0002-0432-2635

J. Jeyanathan (1) https://orcid.org/0000-0002-6056-8162

X. P. Jing $\odot$ https://orcid.org/0000-0003-1759-9366

N. De Neve @ https://orcid.org/0000-0002-7321-9674

L. Vandaele (ㄴ) https://orcid.org/0000-0002-4563-6796

V. Fievez @ https://orcid.org/0000-0001-5042-6200 